\title{
A Study of the Forcing of the 22-25 June 2006 Coastally Trapped Wind Reversal Based on Numerical Simulations and Aircraft Observations
}

\author{
David A. Rahn And Thomas R. Parish \\ Department of Atmospheric Science, University of Wyoming, Laramie, Wyoming
}

(Manuscript received 28 August 2007, in final form 5 May 2008)

\begin{abstract}
Coastally trapped wind reversals (CTWRs) occur periodically in the lowest several hundred meters of the marine boundary layer west of California and disrupt the northerly flow that typically occurs during summer. South winds and coastal fog or low stratus accompany the CTWR, which propagates northward along the coast. A CTWR was observed off the California coast during late June 2006 that originated in the California Bight and propagated northward to Cape Mendocino during the subsequent 2-day period. This CTWR event was explored by the University of Wyoming King Air research aircraft to document the primary characteristics of the wind reversal. Numerical simulations of the CTWR event using the Weather Research and Forecast modeling system were conducted to compare with observations and to provide a broader picture of the CTWR structure and evolution. An analysis of the forcing mechanisms responsible for the June 2006 CTWR event is presented. It is demonstrated that the mature CTWR for this case is a density current propagating northward along the coast in response to the density gradient found to the north of the CTWR with maximum speed during the nighttime hours. Establishment of the density contrast is largely a result of cloud-top longwave radiative cooling of the stratus that accompanies the CTWR, which serves to cool and deepen the boundary layer during the night. Density contrast between the cloudy CTWR air and the ambient environment is enhanced by the persistent offshore flow to the north of the CTWR with attendant warming and a flattening of the horizontal pressure gradient in the marine layer.
\end{abstract}

\section{Introduction}

During summertime months the low-level airflow over the eastern Pacific Ocean is dominated by the circulation associated with the Pacific high that is typically situated about $1000 \mathrm{~km}$ off the West Coast. Subsidence from the Pacific high establishes a sharp temperature inversion at the top of the well-mixed marine boundary layer (MBL); the depth of the MBL increases to the west and thus significant horizontal gradients of potential temperature are found in the nearshore environment. A strong low-level coastal jet (CJ) is commonly found embedded within the broad northerly winds in response to the sloping inversion (e.g., Beardsley et al. 1987; Zemba and Friehe 1987; Burk and Thompson 1996; Rodgers et al. 1998; Parish 2000; Pomeroy and Parish 2001; Rahn and Parish 2007). The northerly wind

Corresponding author address: David A. Rahn, Department of Atmospheric Science, University of Wyoming, Laramie, WY 82071.

E-mail: darahn@uwyo.edu regime is disrupted at times by coastally trapped wind reversals (CTWRs) that are characterized by a southerly wind and coastal fog or stratus adjacent to the coastline that extends westward about $100 \mathrm{~km}$ (e.g., Bond et al. 1996; Ralph et al. 1998; Nuss et al. 2000). CTWRs propagate northward along the coastline at varying speeds dependent on a variety of factors including the time of day (Jackson et al. 1999; Ralph et al. 2000; Nuss et al. 2000). Northward CTWR progress is enhanced during nighttime hours and is often stalled or can even retreat southward during the day (Bond et al. 1996).

Propagating CTWRs have a classic synoptic signature as described in Bond et al. (1996) and Nuss (2007). Strong ridging from the surface to about $700 \mathrm{hPa}$ is present over the Pacific Northwest and extends southward to northern California in the days prior to the onset of a CTWR. There is evidence that in some cases the thermal low situated over the desert southwest may migrate westward in response to the large-scale ridging to the north. This is often associated with a large area of a weak horizontal pressure gradient force (PGF) over the coastal environment off the California coast. As a 
result of the synoptic circulation pattern, an offshore flow pattern develops over a broad region from Oregon and northern California southward, extending to the California Bight in some cases. A normal summertime surface pressure field in the near-coastal margin consists of an alongshore PGF directed southward. During periods of low-level offshore winds, low pressure becomes established near the coast and the direction of the pressure gradient can reverse so that lower pressures are found to the north. It is during such periods of extended offshore flow that propagating CTWRs most commonly develop (Nuss 2007).

Coastal mountains with heights ranging between 300 and $800 \mathrm{~m}$ extend along the West Coast from California northward. Note that the coastal mountain chain is interrupted by a significant gap near San Francisco (see Fig. 1). The coastal mountains are generally above the top of the MBL, thereby serving as a barrier to the onshore movement of stable air. A number of theories have been proposed to explain the forcing of CTWRs. Dorman (1985) first suggested that CTWRs represent topographically trapped internal Kelvin waves in the MBL where the variation in the height of the MBL was the primary forcing mechanism. Reason and Steyn (1992) and Ralph et al. (2000) also discuss CTWRs as possible Kelvin waves. Other CTWR interpretations include trapped density currents or internal bores (Dorman 1987; Mass and Albright 1987), a direct ageostrophic response to the synoptic-scale pressure pattern (e.g., Mass and Bond 1996; Guan et al. 1998), and as a topographic Rossby wave (Skamarock et al. 1999). It has also been proposed that a combination of mechanisms may ultimately be responsible and change over the evolution of the CTWR (Samelson and Rodgerson 1996; Skamarock et al.1999; Reason et al. 2001). Challenging aspects of this problem include the spatial and temporal scales of the CTWR and the interaction with coastal processes and topographic influences. As noted by Skamarock et al. (1999) the stratus finger associated with the CTWR has a length scale consistent with the internal Rossby radius of deformation and thus appears to be rotationally trapped by the coastal topography.

Observational CTWR data are sparse (Nuss et al. 2000). Airborne observations have been conducted during the well-documented 10-11 June 1994 CTWR by Bane (1997) as well as weaker CTWR events during the 1996 Coastal Waves program. Modeling studies have often been conducted to help interpret the limited observations (e.g., Samelson and Rodgerson 1996; Thompson et al. 1997; Jackson et al. 1999; Skamarock et al. 1999). A summary of numerical simulations of CTWRs can be found in Nuss et al. (2000). The purpose

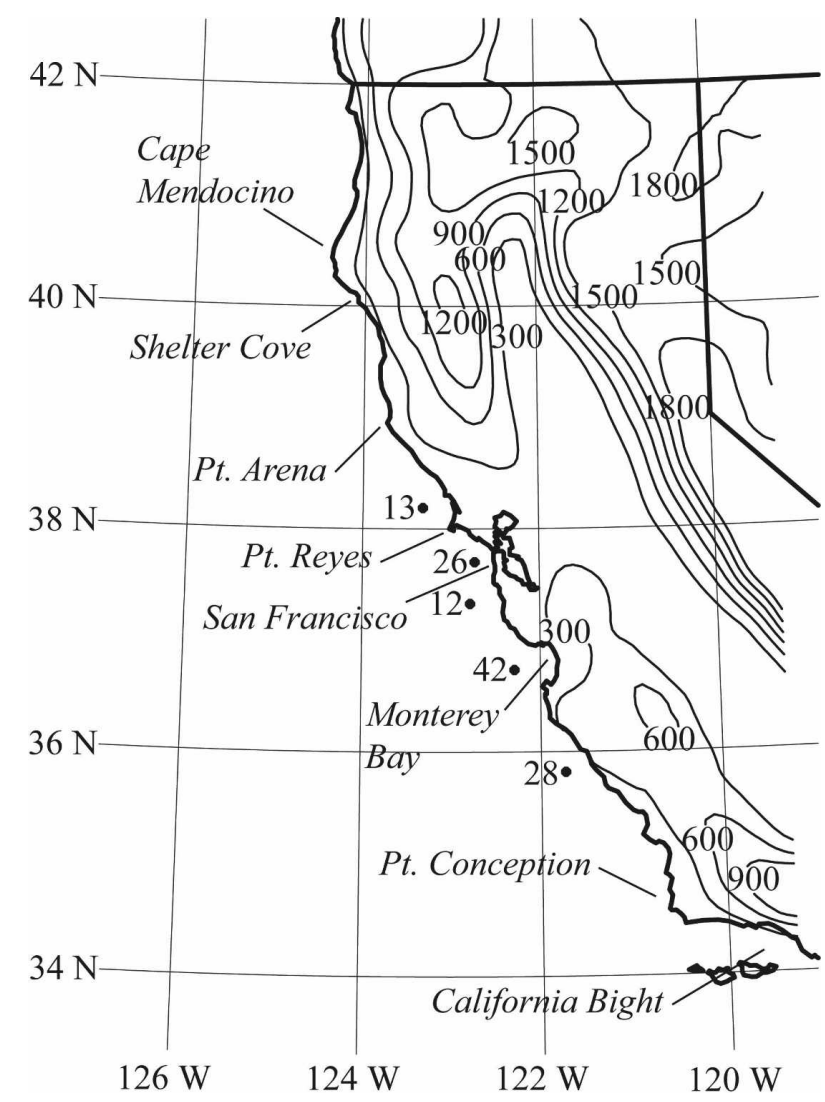

FIG. 1. Topographic map using the 9-km resolution domain with significant geographic features labeled. Contours of terrain every $300 \mathrm{~m}$. The numbers $\mathrm{xx}$ represent buoys numbered $460 \mathrm{xx}$ by NDBC.

of this paper is to address the forcing of the 22-25 June 2006 CTWR. Four flights were conducted by the University of Wyoming King Air research aircraft (UWKA) during this case (Parish et al. 2008, hereafter PRL). The focus of this paper will be the results from numerical simulations of the 22-25 June 2006 event using the Advanced Research Weather Research and Forecasting (WRF) model. Details of WRF can be found in Skamarock et al. (2005). Observational data from the UWKA are compared with the numerical simulation results and provide valuable finescale information on the CTWR event.

The 22-25 June 2006 CTWR can be identified by a narrow band of low cloud adjacent to the coastline. Figure 2 illustrates the progression of the CTWR. It commences at roughly 0000 UTC 22 June (note that local time is UTC minus $7 \mathrm{~h}$ ) just north of the California Bight and moves northward into Monterey Bay by 1800 UTC and farther north to the San Francisco Bay region by 0000 UTC 23 June. The CTWR clouds extend northward past Point Arena by 0000 UTC 24 June and to Cape Mendocino by 0000 UTC 25 June. Buoy obser- 


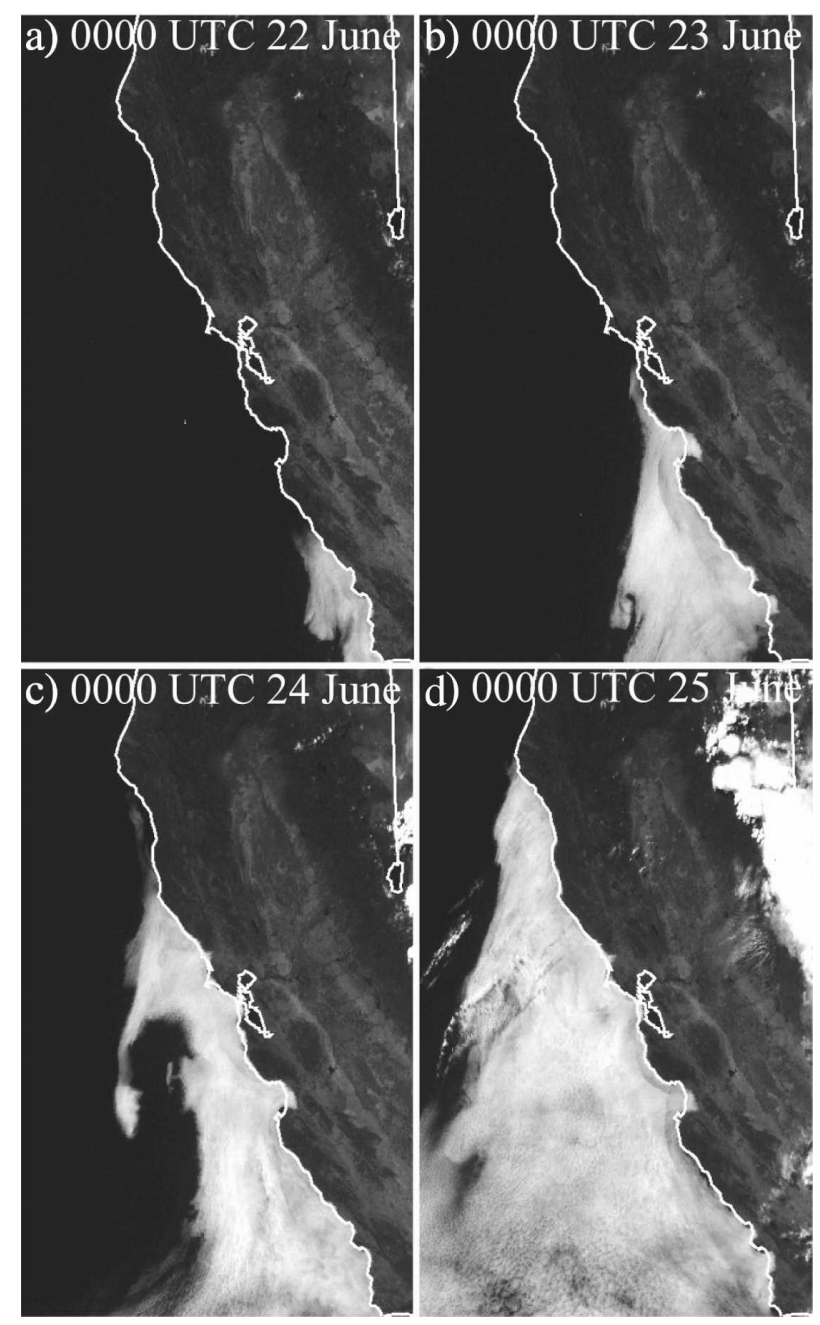

FIG. 2. Visible Geostationary Operational Environmental Satellite-11 (GOES-11) satellite imagery at 0000 UTC (a) 22, (b) 23, (c) 24, and (d) 25 Jun 2006.

vations (not shown) indicate that the wind reversal propagates at an average speed of $4.3 \mathrm{~m} \mathrm{~s}^{-1}$ from 1200 UTC 22 June to 1200 UTC 23 June. This propagation speed is slow, but not unexpected because the CTWR is moving past a large gap in the terrain near San Francisco. Previous research has shown that this topographic feature slows the propagation speed (Reason et al. 2000).

\section{Numerical simulation of the 22-25 June 2006 CTWR event}

\section{a. WRF Model overview and synoptic conditions}

Simulation of a CTWR from its initiation to its decay stage is necessary before forcing mechanisms can be examined with some assurance that the actual physical

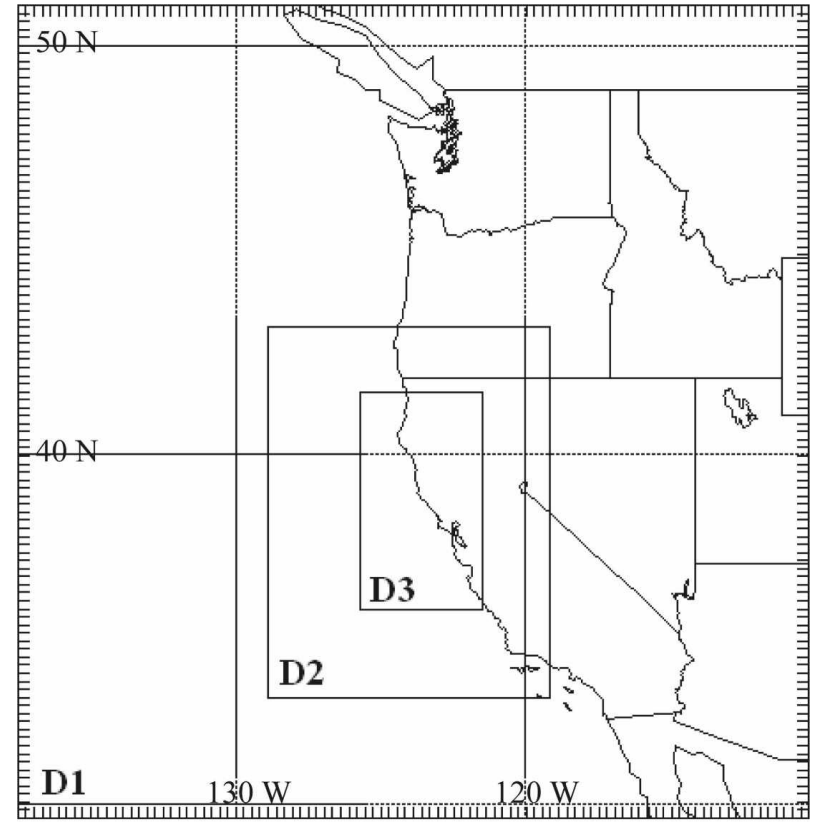

FIG. 3. Model domains used in the WRF simulation. The mother domain (D1), the outer domain (D2), and the inner domain (D3) are bounded by the boxes and correspond to a resolution of 27,9 , and $3 \mathrm{~km}$, respectively.

processes are properly simulated. It is imperative that both the spatial extent of the reversal with its associated cloud layer and the timing of the northward movement of the CTWR are captured successfully. For the 22-25 June 2006 CTWR, a number of WRF simulations have been conducted to depict the wind reversal at various stages of its evolution. Three domains were used in the WRF simulations with the mother domain, outer, and inner domains having 27-, 9-, and 3-km resolution, respectively (Fig. 3). Fifty vertical levels were used with enhanced resolution at low levels. The first level corresponds to a height of about $8 \mathrm{~m}$ above the surface. Vertical resolution increases from approximately $10 \mathrm{~m}$ near the surface to about $40 \mathrm{~m}$ at $500 \mathrm{~m}$ above the surface. Parameterizations utilized in this run are the following: Purdue-Lin microphysics scheme, the Rapid Radiative Transfer Model longwave scheme, Dudhia shortwave, Monin-Obukhov (Janjic) surface scheme, Noah land surface model, Mellor-Yamada-Janjic PBL, Betts-Miller-Janic cumulus, second-order turbulence and mixing, and a horizontal Smagorinsky first-order closure eddy coefficient. Tests also have been conducted using different parameterization settings. It is worth noting that the basic CTWR development is fairly robust and only minor variations in the positioning and timing of the CTWR layer were simulated. The parameterization suite described above appeared to 

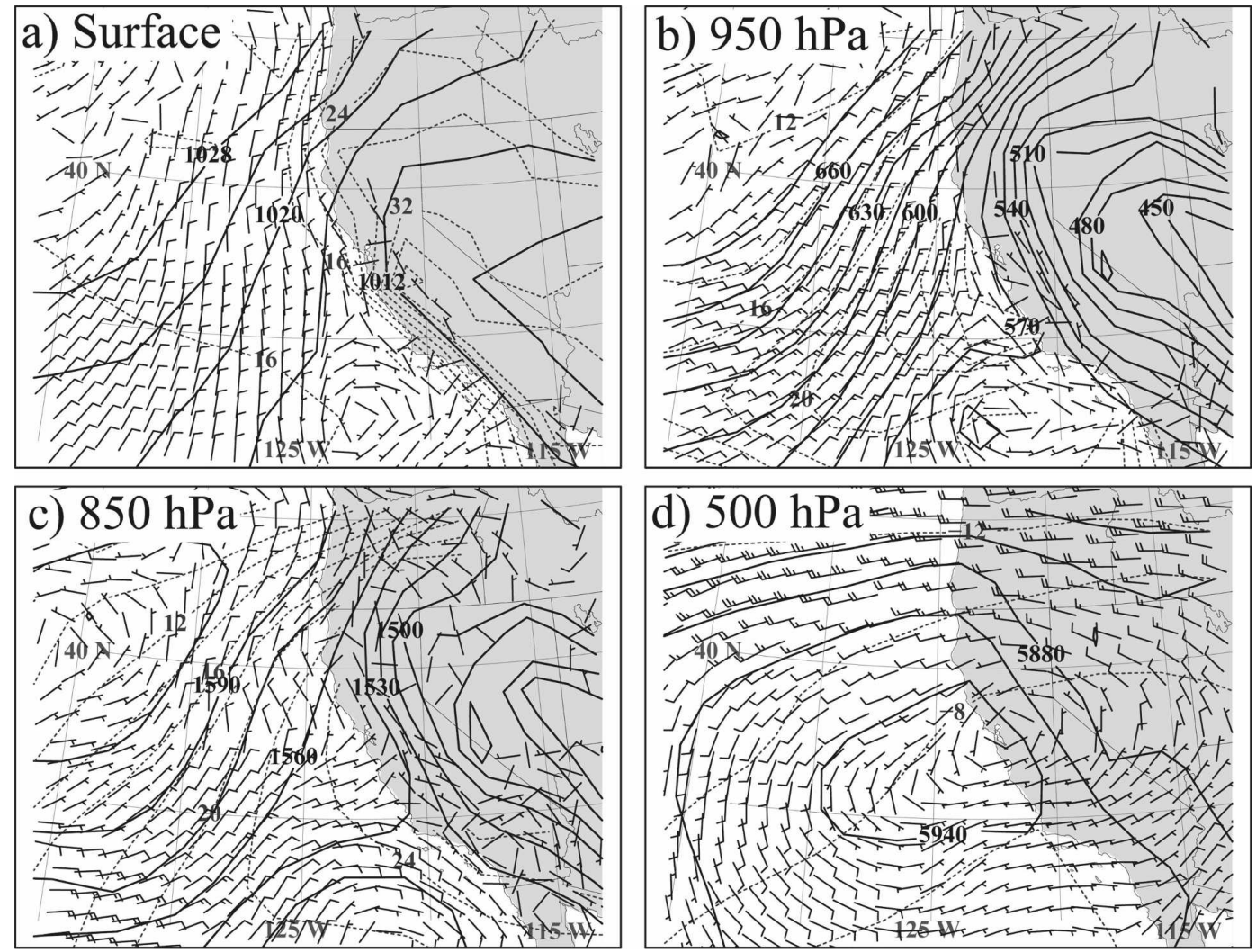

FIG. 4. Depictions of (a) sea level pressure (solid, hPa), surface temperature (dashed, ${ }^{\circ} \mathrm{C}$ ), and 10-m wind barbs (kt) over the ocean; (b) 950-hPa geopotential heights (solid, m), temperature (dashed, ${ }^{\circ} \mathrm{C}$ ), and wind barbs (kt); (c) 850-hPa geopotential heights (solid, m), temperature (dashed, ${ }^{\circ} \mathrm{C}$ ), and wind barbs (kt); and (d) 500-hPa geopotential heights (solid, m), temperature (dashed, ${ }^{\circ} \mathrm{C}$ ), and wind barbs (kt) based on 0000 UTC 23 Jun 2006 forecast from the outermost WRF domain.

yield results that compared most favorably to the UWKA observations. Here we describe results of a 36-h forecast simulation commencing at 0000 UTC 23 June 2006. The 12-km North American Mesoscale (NAM) model 218 grid was used to initialize the simulation and provided mother domain boundary conditions that were updated every $3 \mathrm{~h}$.

Synoptic conditions for 0000 UTC 23 June are summarized by four maps shown in Fig. 4 that are taken from the outermost domain of the WRF simulation. The Pacific high has stretched to the northeast and extends over the Pacific Northwest. A weak cyclonic circulation has developed southwest of California. This pattern is also seen in the 950 -hPa height field. Offshore flow at $950 \mathrm{hPa}$ extends from Oregon southward to approximately Cape Mendocino. Note the strong warming that has occurred over the Pacific west of central California; the $28^{\circ} \mathrm{C}$ isotherm at $950 \mathrm{hPa}$ extends $100 \mathrm{~km}$ offshore from San Francisco. Strong offshore flow is also indicated at $850 \mathrm{hPa}$ with isotherms again reflecting advection of continental air over the marine environment. At $500 \mathrm{hPa}$, a ridge has developed over the coast with a cutoff anticyclone centered just southwest of San Francisco.

\section{b. Model results of CTWR}

Figure 5 illustrates comparisons of the observed satellite images of the stratus and modeled CTWR cloud water from the innermost 3-km nest for four time periods 0200 UTC 23 June-0200 UTC 24 June. WRF cloud cover here is defined by any single level containing cloud liquid water content (LWC) greater than 0.1 $\mathrm{g} \mathrm{kg}^{-1}$. The $10-\mathrm{m}$ wind is represented by vectors and streamlines in each figure. Before sunset at about 0200 UTC 23 June (Figs. 5a,b), low clouds have reached San Francisco Bay with a WRF-simulated maximum southerly wind near $6 \mathrm{~m} \mathrm{~s}^{-1}$ at Monterey Bay. Evidence of stratus intrusion into Monterey Bay that is apparent in the satellite image is well simulated by WRF. By 1400 UTC (Figs. 5c,d), the stratus tongue has reached Point Arena. A cyclonic eddy can be seen in the imagery that has formed southwest of Point Arena; WRF replicates 
this feature although with the center of circulation somewhat farther to the north. By 2000 UTC (Figs. $5 \mathrm{e}, \mathrm{f})$, satellite imagery shows a well-developed cyclonic vortex with the center of circulation primarily west of San Francisco. WRF captures this circulation quite well although the cloud extent within the cyclonic circulation is slightly more than what is observed. This vortex continues to develop such that by 0200 UTC 24 June cyclonic circulation stretches to nearly $36^{\circ} \mathrm{N}$.

That WRF is able to replicate the cloud cover and the progression of the northward movement of the CTWR along the coast is encouraging and provides reason to believe that the model is able to simulate key forcing mechanisms. Figure 6 shows the 996-hPa heights, winds, and temperatures from WRF that are coincident with the images and simulation results shown in Fig. 5 with an additional nighttime image at 0800 UTC. This level was selected since it corresponds to the primary isobaric level at which the UWKA collected data on that same day (see PRL) and represents the approximate top of the stratus deck at the CTWR head. It should be pointed out that both UWKA observations and WRF simulations show that the southerly winds are found throughout a deeper layer of the atmosphere than the cloud layer.

Figure 6a illustrates conditions at 0200 UTC 23 June and shows the narrow strip of southerly wind associated with the CTWR layer that is tight to the coast and stretches to the San Francisco region. Temperatures within the CTWR at $996 \mathrm{hPa}$ are colder than those either to the north or west, implying that the CTWR layer is of higher density. Note the warm temperatures to the north of the CTWR, indicative of offshore flow aloft and subsidence (e.g., Mass and Steenburgh 2000). Results shown in Fig. 6 suggest that the local terrain can enhance the subsidence. Localized warm temperature anomalies are found south of points and capes such as near Point Arena. The proximity of strong subsidence and local warming with the cool, dense CTWR implies a significant density difference near the head of the CTWR. Height contours at 0200 UTC indicate that the PGF in the coastal environment south of approximately Point Arena is weak with higher heights to the south indicating a reversal in the normal pressure field. To the north of Point Arena, heights increase indicating an adverse environment for continued northward movement of the CTWR. This is in agreement with observations taken by the UWKA (see PRL). Little evidence of damming of the cool CTWR layer by the coastal mountains with concurrent ridging along the coast to the south of San Francisco is seen during this time. Height contours do not display a significant increase toward the shore. Any topographic trapping that exists must be weak and it is apparent that no quasigeostrophic balance has become established near the CTWR head. Winds to the south of Monterey Bay are weak, while there are significant accelerations into San Francisco Bay, driven by the large thermal contrast. Cross-shore wind components are weak in the nearcoast region with evidence of the thermal upslope flow over land.

Figure $6 \mathrm{~b}$ is taken from 0800 UTC, corresponding to 0100 local time. Significant changes in the position and extent of stratus clouds have taken place during the evening hours (see Fig. 5). The CTWR has progressed to just south of Point Arena and the coastal environment at $996 \mathrm{hPa}$ has cooled by at least $3^{\circ} \mathrm{C}$ and in some locations by nearly $5^{\circ} \mathrm{C}$. Note that isotherms mark the approximate position of the wind reversal and that the density contrast between the cloudy CTWR layer and surrounding environment has increased throughout the nighttime hours. It is proposed here and discussed in section 4 that this cooling is primarily the result of longwave radiative flux divergence at the top of the cloud layer. Cloud-top cooling of the marine stratus has been investigated by a number of authors (e.g., Oliver et al. 1978) and the simulated increase in cloud thickness is consistent with previous studies. The large contrast in temperature created between the two regions provides evidence of the strong density contrast that exists at the CTWR edge. Warmer temperatures remain to the north of the CTWR head, although there is evidence of reduced offshore flow as compared to $6 \mathrm{~h}$ earlier as shown in Fig. 6a.

Note the adjustment in the 996-hPa height contours in the near-coastal environment to the south of San Francisco from 0200 to 0800 UTC. A northwarddirected horizontal pressure gradient of about $1 \mathrm{hPa}$ $(100 \mathrm{~km})^{-1}$ is present. Some of this adjustment is thought to be the result of the CTWR cooling. A 500-m layer that cools $5^{\circ} \mathrm{C}$ is equivalent to a $1-\mathrm{hPa}$ pressure increase.

By 1400 UTC (Fig. 6c), the coldest air at $996 \mathrm{hPa}$ (and hence the most dense air) of about $9^{\circ} \mathrm{C}$ is associated with the CTWR. Additional northward movement of the CTWR density current requires an ambient horizontal pressure gradient force in the layer of air above the CTWR that is weak or even directed from south to north. Warmest 996-hPa temperatures over the ocean have moved northward and a weak low pressure center that represents the beginning of the vortex is found to the west of Point Arena. Winds from south of Monterey Bay to past Point Arena are directed downgradient in Fig. 6c at 1400 UTC with lower heights to the north and must therefore be significantly ageostrophic. Note that some evidence exists for blocking of 


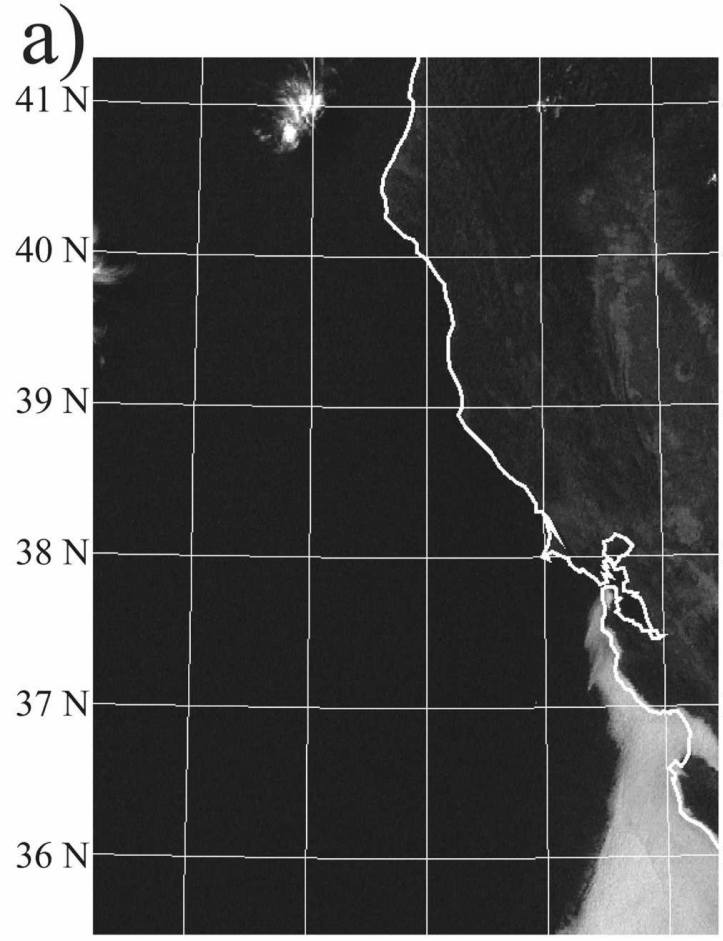

$126 \mathrm{~W} \quad 125 \mathrm{~W} \quad 124 \mathrm{~W} \quad 123 \mathrm{~W} \quad 122 \mathrm{~W}$

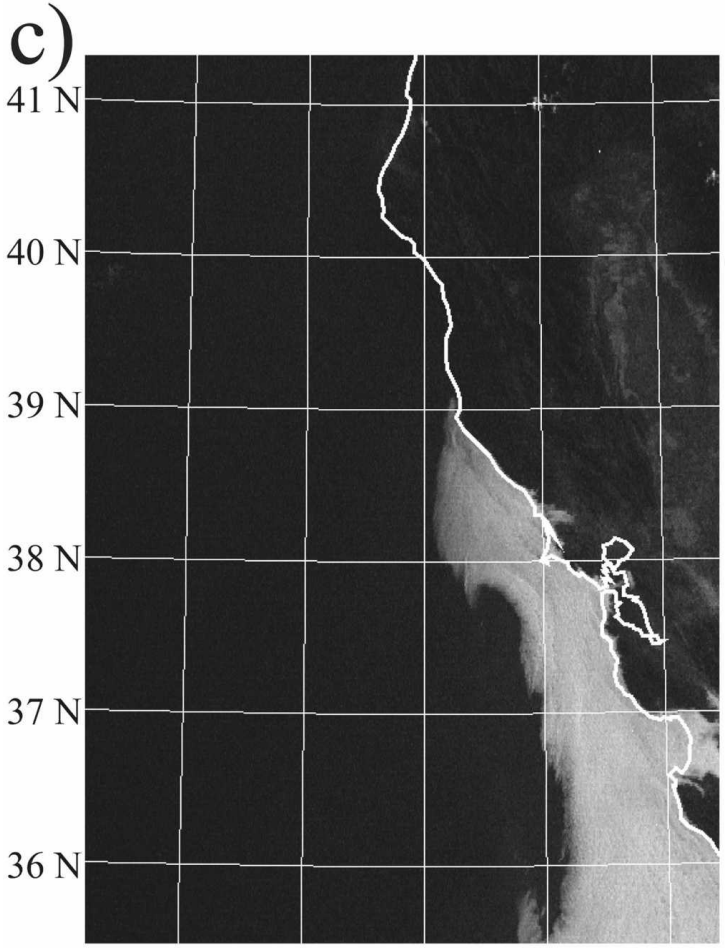

126 W 125 W 124 W 123 W 122 W b)

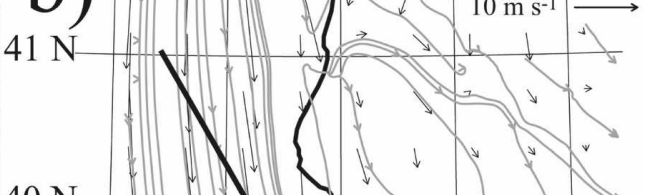

$40 N$

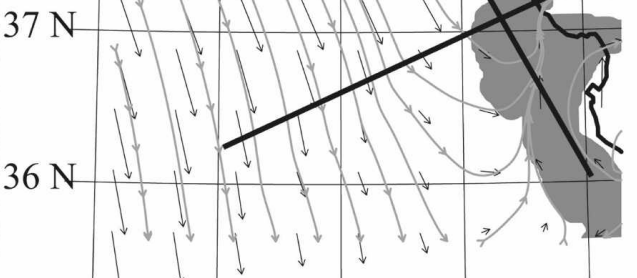

$126 \mathrm{~W} \quad 125 \mathrm{~W} \quad 124 \mathrm{~W} \quad 123 \mathrm{~W} \quad 122 \mathrm{~W}$

d)

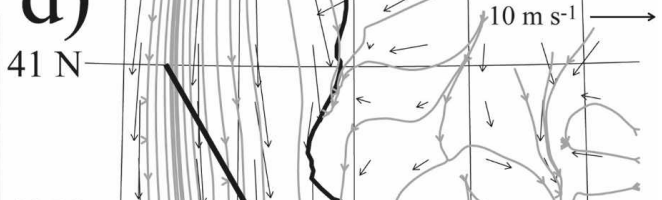

$40 \mathrm{~N}$
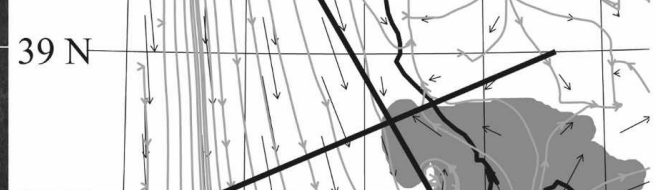

$38 \mathrm{~N}$

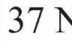

$36 \mathrm{~N}$

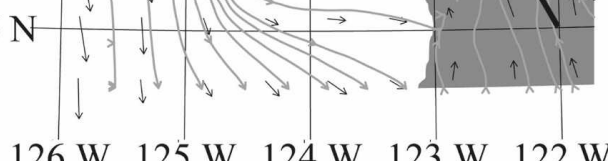

FIG. 5. (left) Visible satellite image and (right) model-simulated cloud cover with 10-m wind streamlines and vectors at (a), (b) 0200; (c), (d) 1400; and (e), (f) 2000 UTC 23 Jun and (g), (h) 0200 UTC 24 Jun 2006. Cross-section locations at each time are indicated by the solid, thick line. The 0800 UTC cross section is indicated by the dashed, thick line. 

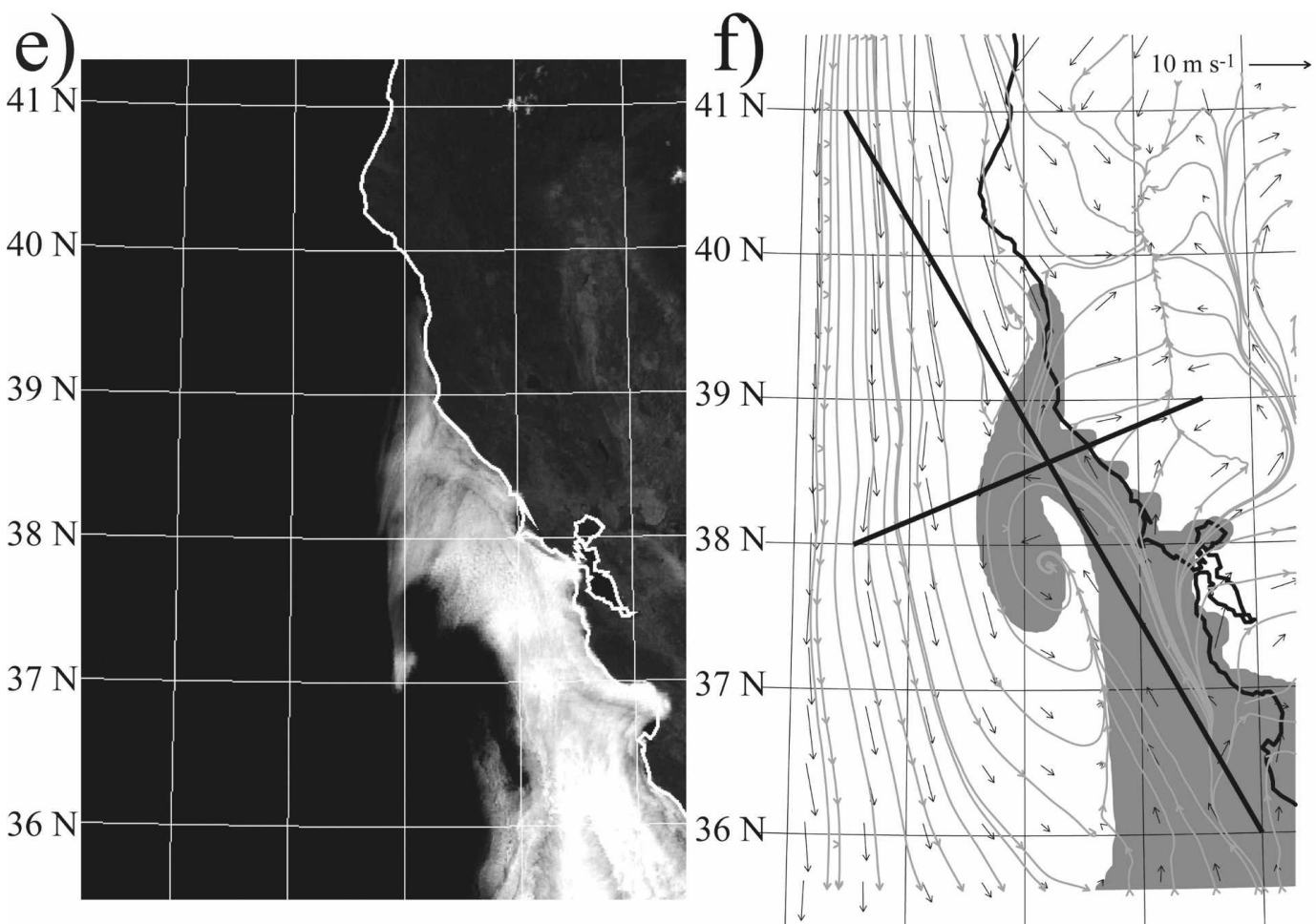

126 W 125 W 124 W 123 W 122 W

126 W 125 W 124 W 123 W 122 W
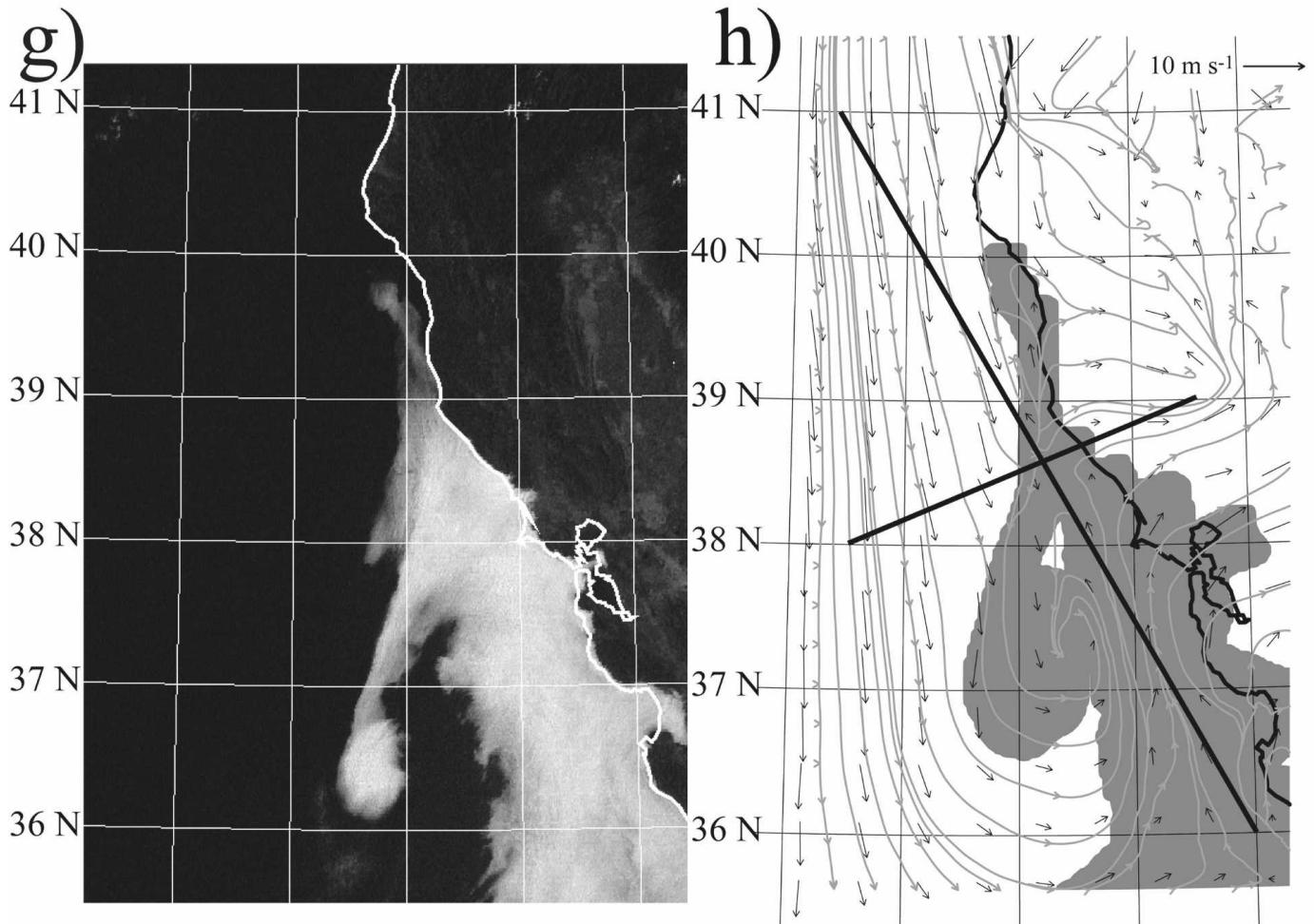

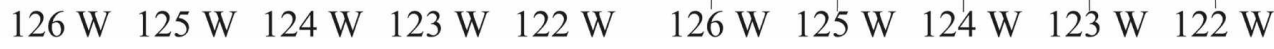
FIG. 5. (Continued) 

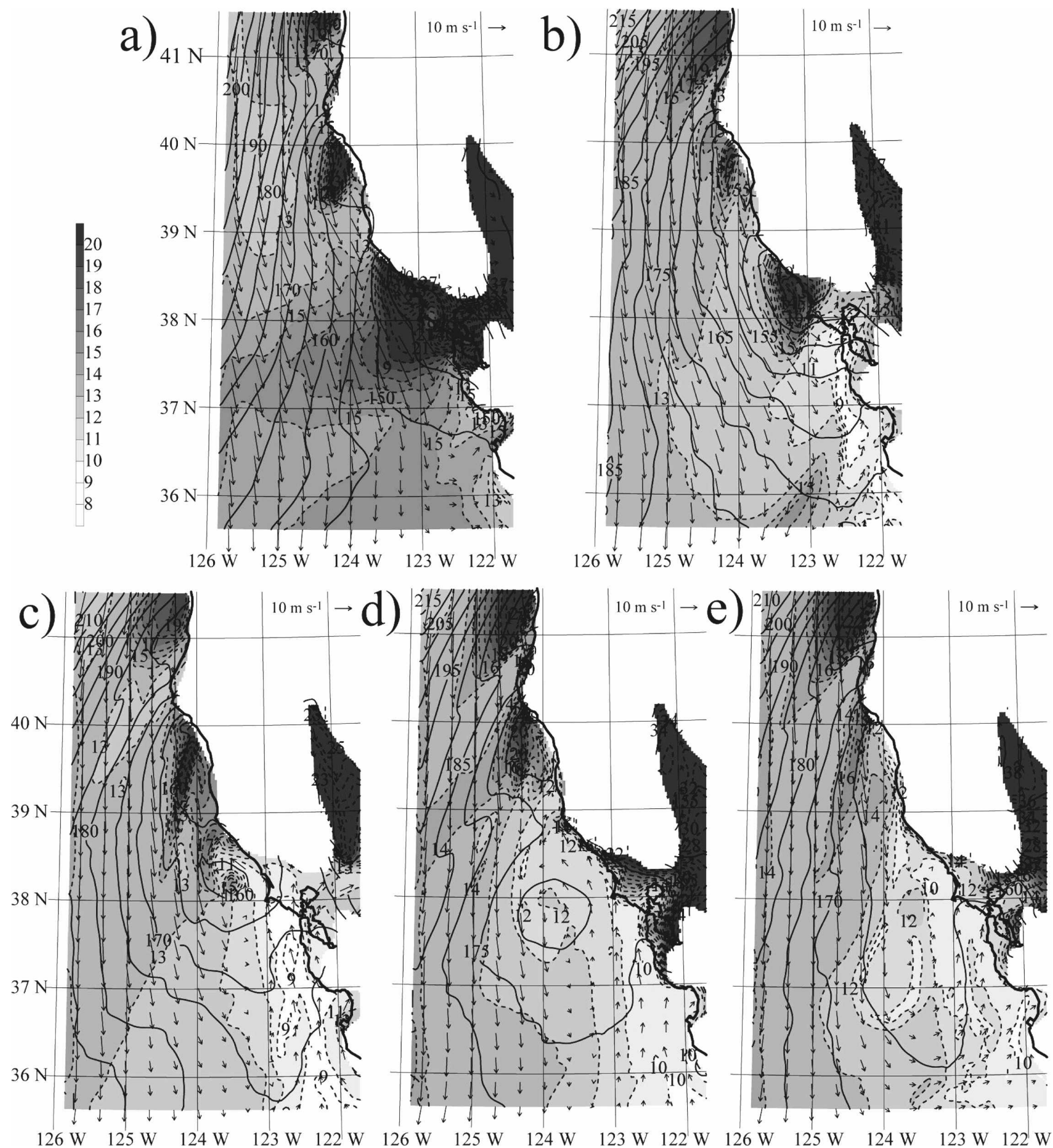

FIG. 6. The 996-hPa geopotential height (solid contours, 5-m interval), temperature (grayscale/dashed line, every $1^{\circ} \mathrm{C}$ ), and wind vectors at (a) 0200, (b) 0800, (c) 1400, and (d) 2000 UTC 23 Jun and (e) 0200 UTC 24 Jun 2006.

cold CTWR air by the coastal terrain to the south of San Francisco Bay, although the amplitude is less than $0.5 \mathrm{hPa}$.

At 2000 UTC (Fig. 6d) the CTWR at $996 \mathrm{hPa}$ continues to be cooler and more dense than the ambient environment despite the solar radiative input. Note that the isotherms follow the cloud edge of the CTWR, suggesting the importance of the stratus layer in maintaining the density contrast. The southerly surge has now reached past Point Arena and the circulation about the low pressure area becomes more pronounced. Some studies of CTWRs have indicated the importance of 
cyclonic circulations as mechanisms to prompt initiation and propagation (e.g., Nuss et al. 2000). In this case it is apparent that the CTWR had already progressed east of the cyclonic circulation and may be in part responsible for the cyclone development in that it separates the warm temperatures south of Point Arena with the cool and dense CTWR layer. The cyclonic circulation becomes more diffuse by 0200 UTC 24 June (Fig. 6 e) as the localized warm air anomaly is not sustained and the head of the CTWR layer has reached just south of Cape Mendocino. Modeled southerly flow components within the CTWR display a decrease throughout the daytime hours and are quite weak north of San Francisco.

One prominent feature of the CTWR cloud structure shown in Figs. 3c and 5e,g and model output shown in Figs. 6c,d is the large eddy situated west of Point Reyes and to the south of Point Arena that becomes established during the daytime hours on 23 June. Mass and Bond (1996) and Nuss et al. (2000) note the importance of the lee trough and its northward progression in the interpretation of a CTWR as a mesoscale response to the along-coast pressure gradient. Cyclonic eddy formation near Point Arena is not limited to this CTWR case. Burk and Thompson (2004) note that a "Point Arena eddy" was observed in the 28 August 2002 CTWR case. From Fig. 6c it is apparent that the CTWR has reached past Point Reyes and is near Point Arena in the visible imagery at 1400 UTC. Results from the WRF simulation at this time have the cloud boundary a little to the south of what is observed. The head of the CTWR is north of the position where the cyclonic circulation first appears and hence it is unlikely that the development of the eddy is responsible for the stratus surge. From the WRF simulation at 1400 UTC, the cloud region associated with the CTWR remains cooler than the ambient environment to the west with a strong density contrast near the head.

To further illustrate the importance of the clouds and their demarcation of regimes, a plot of the $10-\mathrm{m}$ wind and divergence at 0800 UTC 23 June is shown in Fig. 7. Strong convergence $\left(\sim 3 \times 10^{-4} \mathrm{~s}^{-1}\right)$ is depicted in a band extending southwest from Point Reyes near the head of the CTWR. Thompson et al. (2005) have reported a similar feature. Note that this region of convergence is orientated along the strong temperature gradient seen at the same time (Fig. 6b) and weakens offshore as does the temperature gradient. Another major region of convergence is located along the western boundary of the cloud edge throughout the domain. There is no significant convergence along the coast within the CTWR, which is consistent with the lack of

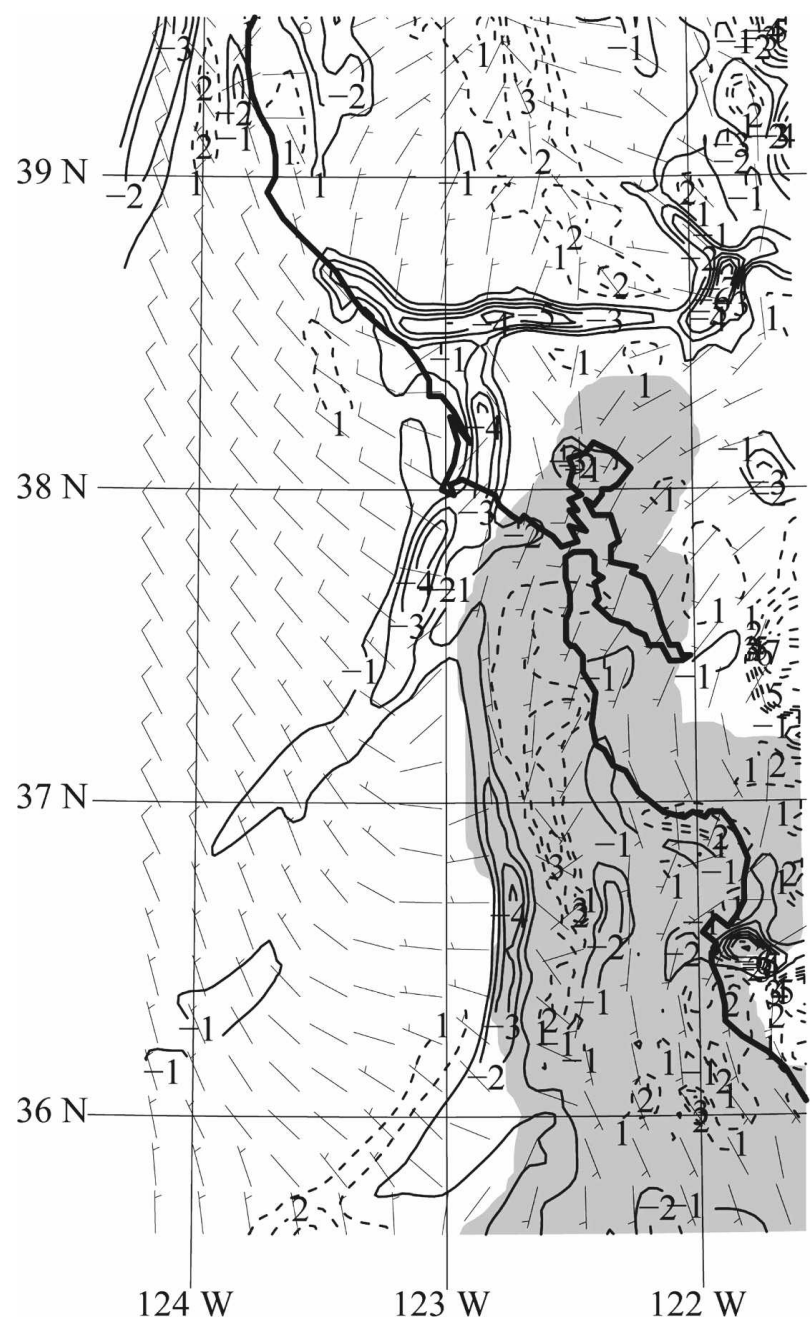

FIG. 7. The $10-\mathrm{m}$ wind barbs $\left(\mathrm{m} \mathrm{s}^{-1}\right)$ and divergence of the $10-\mathrm{m}$ wind $\left(10^{-4} \mathrm{~s}^{-1}\right)$ at 0800 UTC 23 Jun 2006. Dashed lines represent divergence and solid lines represent convergence.

strong coastal damming of an onshore flow by the topography.

It can be concluded that the June 2006 CTWR displays characteristics of a density current that moves northward in a direction that is along the density gradient. Clouds are vital to the establishment of a density contrast. The ambient horizontal pressure field resulting from offshore flow provides the prerequisite initial warming and flattening of the horizontal pressure gradient in the marine environment and also clears the stratocumulus ahead of the CTWR.

\section{c. Model cross sections of the 22-25 June 2006 CTWR}

To examine the vertical structure as represented by WRF, alongshore cross sections have been prepared for 


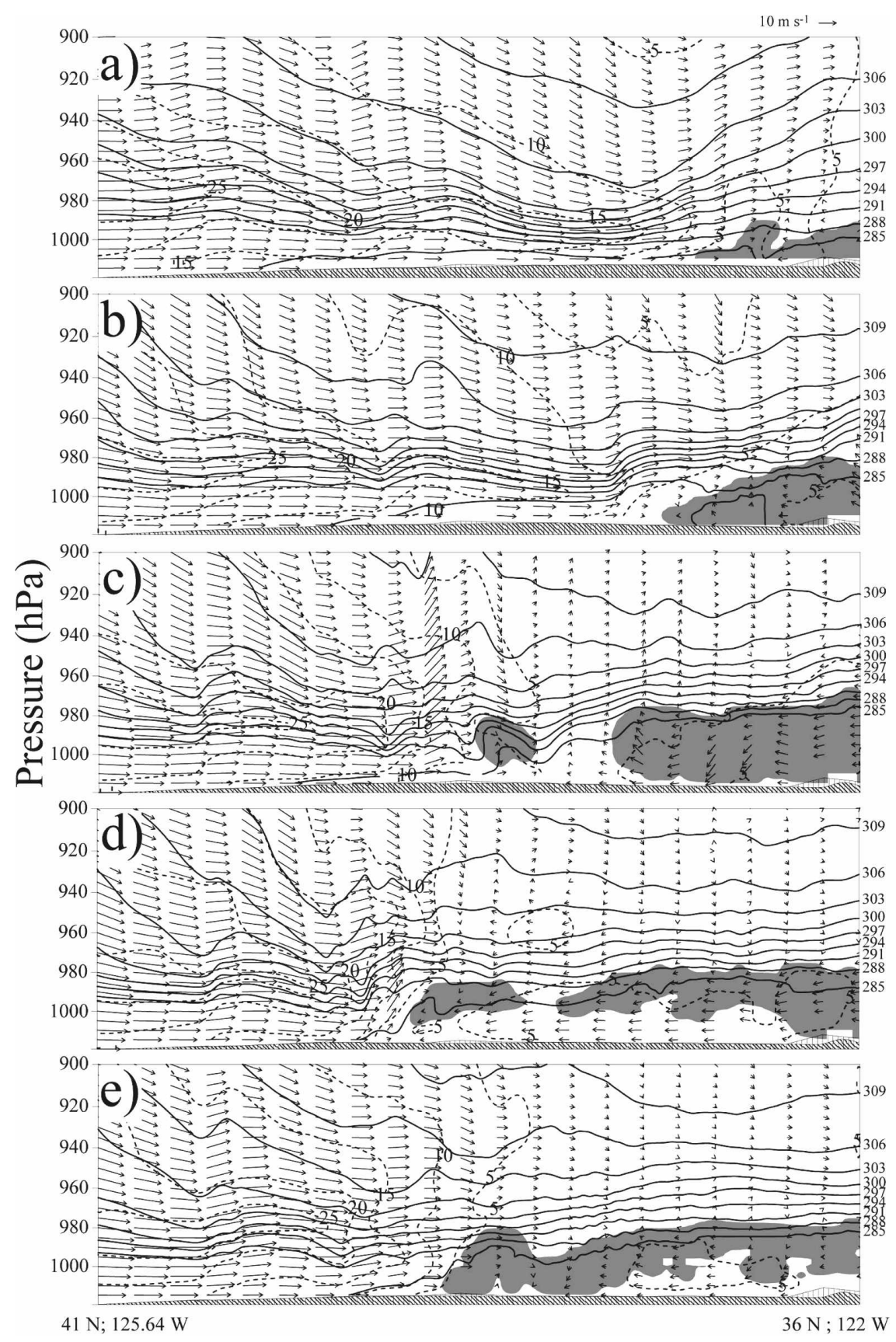

FIG. 8. Alongshore cross sections extending from $41^{\circ} \mathrm{N}, 125.6^{\circ} \mathrm{W}$ to $36^{\circ} \mathrm{N}, 122^{\circ} \mathrm{W}$, (solid lines in Fig. 5) of potential temperature (solid, K), total wind magnitude (dashed, $\mathrm{m} \mathrm{s}^{-1}$ ), horizontal and vertical wind vectors in the plane of the cross section and LWC (grayscale above $0.01 \mathrm{~g}$ $\mathrm{kg}^{-1}$ ) for (a) 0200, (b) 0800, (c) 1400, and (d) 2000 UTC 23 Jun and (e) 0200 UTC 24 Jun 2006.

the times depicted in Fig. 6. Locations of the cross sections can be seen by the solid coast-parallel lines in Fig. 5. At 0200 UTC (Fig. 8a) the CTWR is situated near the southern end of the cross section near Monterey Bay. This time represents the warmest part of the day and the contrast in potential temperature between the
CTWR layer and the ambient environment to the north is weak. Rapid cooling of at the top of the stratus layer occurs after sunset and as seen previously the CTWR becomes better developed in the WRF simulation. Figure $8 \mathrm{~b}$ is taken at 0800 UTC and illustrates the cooling and northward progress of the CTWR layer. Clouds 
associated with the CTWR have increased in thickness (note the upward movement of the isentropes) and spatial extent and a deeper, well-mixed CTWR layer has developed. Temperatures within the CTWR layer are $2^{\circ}-3^{\circ} \mathrm{C}$ colder than to the north or west. Figure $8 \mathrm{~b}$ also shows a cloud-free area near the head of the CTWR that has been lifted by the strong surface convergence where the northerly wind encounters the southerly surge. This is similar to the findings in Thompson et al. (2005) that describe this as a precursor to the fog formation.

As shown in Figs. 5c and 6c, the cyclonic eddy begins to develop at 1400 UTC (Fig. 8c) and thus the alongshore cross section becomes more complicated. The cross-section line passes through the head of the cloud, then a region of relatively clear air before again passing back into the CTWR layer. The CTWR layer remains cool and well mixed. By 2000 UTC (Fig. 8d) the entire CTWR layer has progressed north, although the WRFsimulated stratus layer has decreased in thickness, which is consistent with heating by solar insolation. The CTWR remains cooler and more dense than the environment to the north. Little northward progress is simulated throughout the remainder of the day such that by early evening on 0200 UTC 24 June (Fig. 8e) the head of the CTWR remains to the south of Cape Mendocino.

It has been suggested that blocking is a significant feature of CTWRs and that large variations in the depth of the MBL may exist in the cross-shore direction. Cross sections in the cross-shore direction (Fig. 9) have been prepared to examine the role of blocking and variations in state parameters. Locations of the crossshore cross sections are shown by bold lines normal to the coastline in Fig. 5. Careful inspection of the cross sections reveals a close connection between the stratus layer and the isentrope orientation. Not surprisingly, coldest potential temperatures are associated with the stratus and significant gradients often exist between cloud and cloud-free regions. The early evening 0200 UTC 23 June cross section (Fig. 9a) shows only thin stratus associated with the CTWR. Six hours later after nocturnal cooling of the stratus has taken place, the clouds are significantly thicker with colder potential temperatures. Cross sections at 1400 and 2000 UTC 23 June and 0200 UTC 24 June (Figs. 9c-e) are along the same path and show the northward progression of the CTWR and the evolution of the stratus coverage during the period. While marginal cross-shore variations exist, there is little evidence that significant cross-shore variations in the depth of the MBL are present in any of the cross sections. Isentropes near the top of the MBL are predominantly directed horizontal. Local diabatic cool- ing associated with the clouds are responsible for enhancing the inversion strength, especially at the 0800 UTC 23 June time period (Fig. 9b).

\section{d. WRF forcing of the 22-25 June 2006 CTWR}

Output from WRF can be used to infer the dynamical force balance during the various stages in the CTWR life history. In particular, it is appropriate to inquire as to the forcing of the CTWR during its advancing phase and how that compares with proposed conceptual models. Figure 10 depicts wind barbs, heights, cloud cover, and significant components of the momentum equation. The horizontal equation of motion can be expressed as

$$
\frac{\partial \mathbf{V}}{\partial t}=-\mathbf{V} \cdot \nabla \mathbf{V}-\nabla \Phi-f \mathbf{k} \times \mathbf{V}+\mathbf{R} .
$$

The term on the left-hand side is the local acceleration of the horizontal wind (ACC in Fig. 10, thick black vector). The first term on the right-hand side is the advection (ADV, thick gray vector), the second term is the PGF (black vector), the third term is the Coriolis force (COR, thin black vector), and the final term is the residual (RES, thin gray vector). The residual includes the friction and turbulent mixing.

Emphasis here is placed on the nighttime hours for which the CTWR is best developed. Figure 10a shows the force balance at $1000 \mathrm{hPa}$ in the region surrounding the CTWR at 0800 UTC 23 June. Three basic regions can be identified based on the force balance. In the northwest part of the domain, the wind is quasigeostrophic with the two major components of Coriolis force and PGF; weaker residual terms (friction and turbulent mixing) primarily oppose the wind and there is some acceleration toward the lower heights. A zone of transition occurs near the edge of the CTWR. Northwest flow encounters a PGF that changes rapidly so that it opposes the flow and slows the wind. Large advective and PGF components are present that oppose each other and dominate the force balance. Within the CTWR region just offshore and south of San Francisco Bay, the PGF and the residual (friction and turbulent mixing) are the largest terms so that the force balance is closest to that of an antitriptic balance with little acceleration. Note that the Coriolis force is generally small within the CTWR and hence the southerly flow can only be classified as weakly rotationally trapped.

Figure 10b illustrates components of the momentum equation at $0800 \mathrm{UTC}$ at $990 \mathrm{hPa}$, which is near or above the top of the CTWR stratus (see Figs. $8 \mathrm{~b}$ and $9 b$ ). To the west of the CTWR, flows are approaching a quasigeostrophic balance with the PGF and Coriolis force being the dominant terms in the momentum 


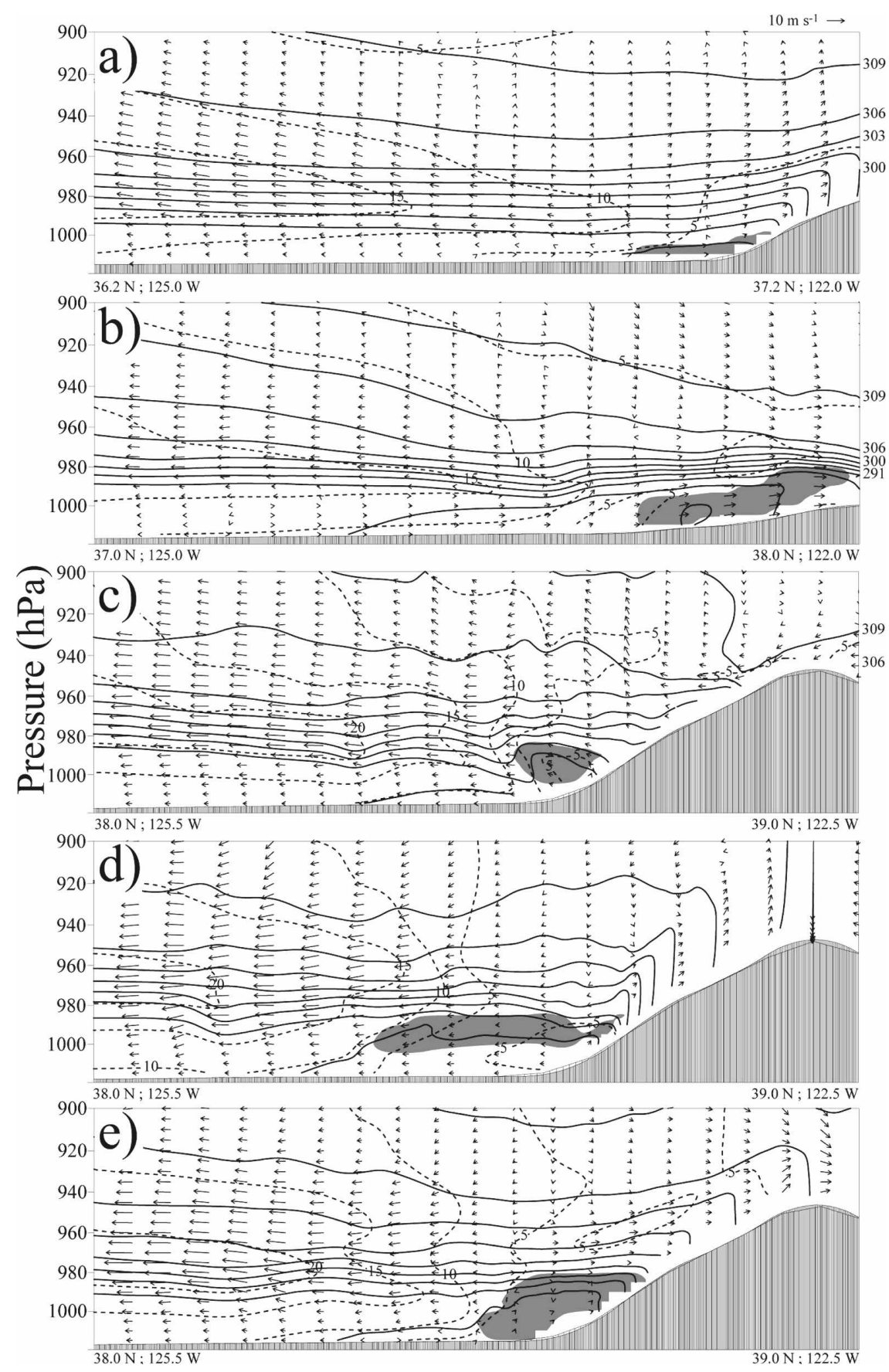

FIG. 9. As in Fig. 7, but for cross-shore cross sections (locations shown by solid lines in Fig. 5; the dashed, thick line represents the 0800 UTC cross section).

equation. Winds within the CTWR show more of a westerly component, highlighting the low-level nature of this CTWR. The CTWR flow remains generally downgradient and the PGF is still the dominant forcing term. Little evidence of blocking can be seen and the small size of the Coriolis force suggests that the flows are weakly influenced by rotation. Wind above the
CTWR continues to shift to the west and then northwest above the CTWR at levels above $990 \mathrm{hPa}$ (not shown) with a force balance that takes on quasigeostrophic characteristics.

Figures 10c,d depict a smaller area focused near the head of the CTWR at 1600 UTC 23 June centered near Point Arena. At $1000 \mathrm{hPa}$ (Fig. 10c) the acceleration is 

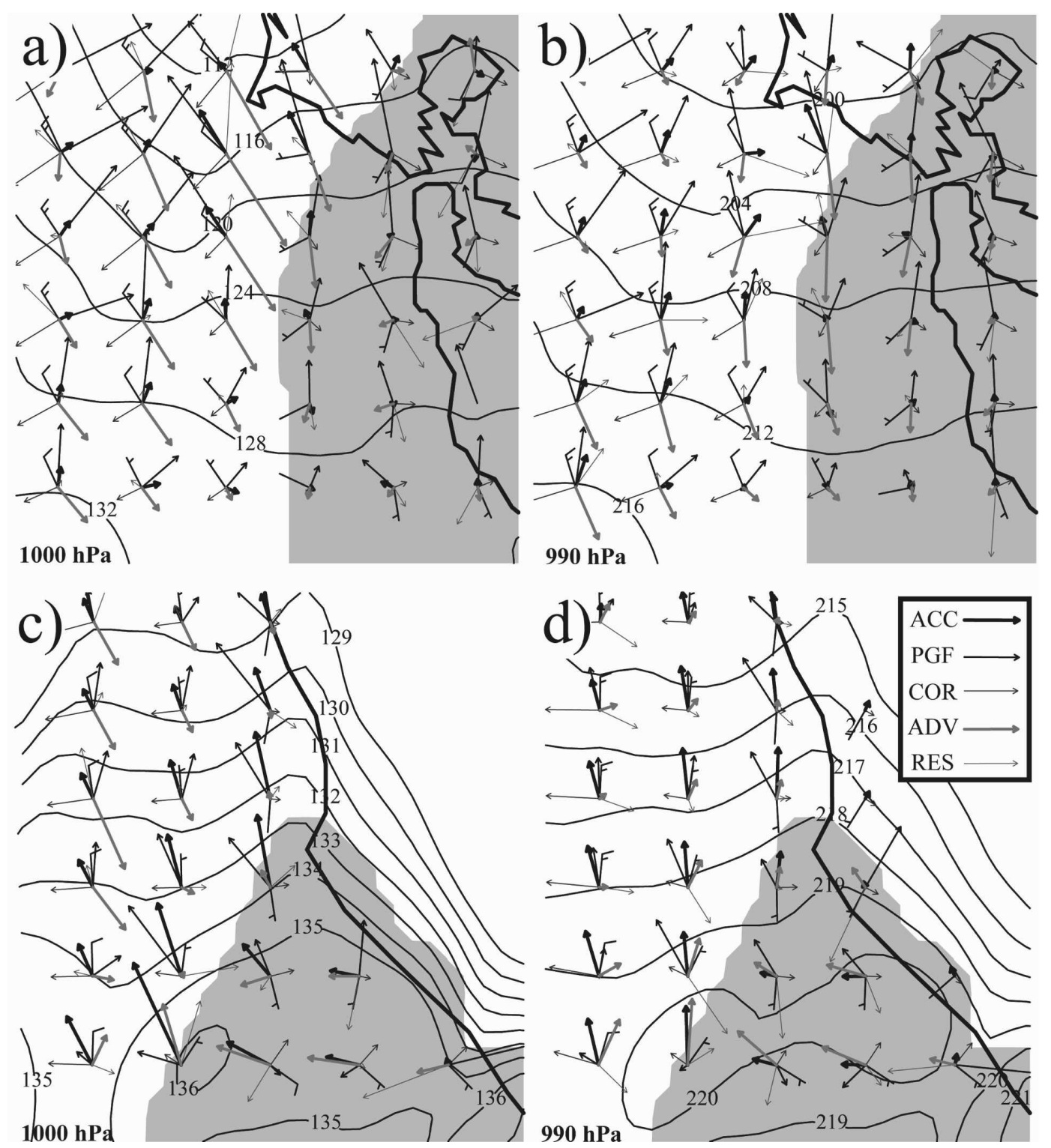

FIG. 10. Wind barbs $\left(\mathrm{m} \mathrm{s}^{-1}\right)$, height contours $(\mathrm{m})$, and LWC greater than $0.01 \mathrm{~g} \mathrm{~kg}^{-1}$ (shaded region) representing the CTWR cloud boundary from the WRF inner grid. Times and heights are (a) $1000 \mathrm{hPa}$ at 0800 UTC 23 Jun, (b) $990 \mathrm{hPa}$ at 0800 UTC 23 Jun (for view centered southwest of San Francisco), (c) $1000 \mathrm{hPa}$ at 1600 UTC 23 Jun, and (d) $990 \mathrm{hPa}$ at 1600 UTC 23 Jun 2006 (for close-up view centered near Point Arena). Terms in the momentum equation are represented by the vectors corresponding to the key in the top right of (d). Abbreviations are given in the text.

northward over most of the domain with a maximum acceleration near the cloud edge. Northwest of the cloud edge is a large advective term as the wind climbs almost directly upgradient and slows. Within the northern portions of the cloud-covered area, the flow is southerly and downgradient so that the PGF is driving the flow to the north. The wind near the head of the CTWR at $990 \mathrm{hPa}$ (Fig. 10d) is still primarily alongshore with a PGF directed to the north.
From Fig. 10, it can be concluded that the flow near the head of the CTWR is not in geostrophic balance. The magnitude of the cross-shore PGF need not be large to block the inland motion of the stratus layer. There is no doubt that the ambient pressure field is induced in large part by synoptic conditions associated with the offshore flow. CTWR motion as simulated by WRF can thus be appropriately described as an ageostrophic acceleration of a density current. UWKA ob- 
servations made at the head of the CTWR several hours later support this assertion.

\section{Airborne observations of the forcing of the 22-25 June 2006 CTWR event}

Observations of the 22-25 June 2006 CTWR were obtained during the Dynamics and Microphysics in Marine Stratocumulus project between 21 May and 30 June 2006 based out of Arcata, California. This project had two main objectives: investigating the links between dynamics and cloud processes within the marine stratocumulus under prevalent conditions (northerly flow along the West Coast) and investigating the forcing and structure of the atmosphere during a CTWR event. For the 22-25 June 2006 CTWR event, flight legs were conducted to sample the vertical structure and to measure the PGF in alongshore and cross-shore directions. Four flights were conducted during the 3-day CTWR event. Here the emphasis is on aircraft observations of the forcing of the CTWR based on two flights from 23 June 2006 during which the CTWR was propagating northward. Details of the state variables observed from the airborne platform during 23 June can be found in PRL.

The UWKA commenced its first flight at 1435 UTC 23 June 2006. After a ferry of approximately $1 \mathrm{~h}$, the UWKA reached the stratus marking the head of the CTWR near Point Arena. As the UWKA approached the CTWR, sawtooth profiles were conducted along the axis of the wind reversal parallel to the coast to capture the vertical structure of the atmosphere adjacent to the reversal. To measure the forcing, it was necessary to directly measure the PGF. Alongshore flight legs of approximately $80 \mathrm{~km}$ were then conducted along the 996-hPa surface (about $170 \mathrm{~m}$ above the ocean and near the top of the stratus layer) between 1728 and 1806 UTC to map the height of the isobaric surface, the slope of which is a measure of the PGF. To account for isallobaric tendencies, reciprocal legs (i.e., return legs along the same line) were conducted. To ensure accurate detection of the PGF, two independent measures were made. Radar altimeters on board the UWKA allow determination of the height of the aircraft above the ocean. In addition, the absolute height above sea level can be determined using differential GPS techniques (Parish et al. 2007). Small deviations of the aircraft from the selected pressure level (typically less than $0.2 \mathrm{hPa}$ ) have been corrected to the $996-\mathrm{hPa}$ isobaric surface using the hydrostatic equation since the temperatures are known to within $0.5^{\circ} \mathrm{C}$. For all isobaric legs, agreement between altimetry-based and GPS-derived geostrophic winds is within $0.5 \mathrm{~m} \mathrm{~s}^{-1}$; re- sults using differential GPS techniques to map the isobaric surface heights will be presented.

Figure 11 shows the corrected GPS isobaric heights from the reciprocal alongshore legs, cross-shore $\left(60^{\circ}\right)$ and alongshore $\left(330^{\circ}\right)$ wind components, and potential temperatures for the $996-\mathrm{hPa}$ isobaric leg. The flight track is shown with respect to the visible satellite image from that time. Isobaric heights of the 996-hPa surface reveal a slope that is directed downward to the north, implying a PGF directed north. The PGF directed along the flight path using data from both legs has a magnitude corresponding to a geostrophic wind of 5 $\mathrm{m} \mathrm{s}^{-1}$ directed onshore, although local isobaric slopes are greater within the CTWR itself. For reference it should be noted that the roughly 4-m height change of the isobaric surface shown in Fig. 10 corresponds to a horizontal pressure change of approximately $0.45 \mathrm{hPa}$. This is consistent with the pressure signal observed by buoys along the coast in response to the wind shift and with results from WRF simulations (e.g., Fig. 10).

Wind components show that the flow is ageostrophic in the alongshore direction. Cross-shore wind components within the CTWR are $2-3 \mathrm{~m} \mathrm{~s}^{-1}$, decreasing to near zero ahead of the surge. This implies a cross-shore ageostrophic wind of a magnitude at least as large as the cross-shore wind within the CTWR and is directed to the west. Given a westward ageostrophic component, the acceleration of the flow must be toward the north. From this it can be inferred that at least a component of the observed alongshore wind must be in response to the ageostrophic alongshore acceleration. It is important to point out that this isobaric leg provides no information on the PGF in the cross-shore direction. Results of subsequent cross-shore isobaric flights however suggest a nearly flat PGF. If it is assumed that only a weak cross-slope PGF exits, the alongshore wind component is largely ageostrophic with an acceleration to the right of the flow and toward the coastal terrain. Model results such as in Fig. 10 suggest a similar force balance at grid points along the eastern side of the CTWR. Potential temperatures along the isobaric leg indicate gradual cooling of $1-2 \mathrm{~K}$ as the plane crosses into the CTWR, evidence that the CTWR layer is more dense than the atmosphere to the north.

It has long been suspected that significant cross-shore changes in pressure should accompany a CTWR. In particular, damming effects such as seen in barrier wind cases (i.e., Schwerdtfeger 1975) can lead to pressure increases of several hectopascals across a distance comparable with the baroclinic radius of deformation. Ralph et al. (1998) suspected that the pressure field increases to the east by about $1 \mathrm{hPa}$ for the 10-11 June 


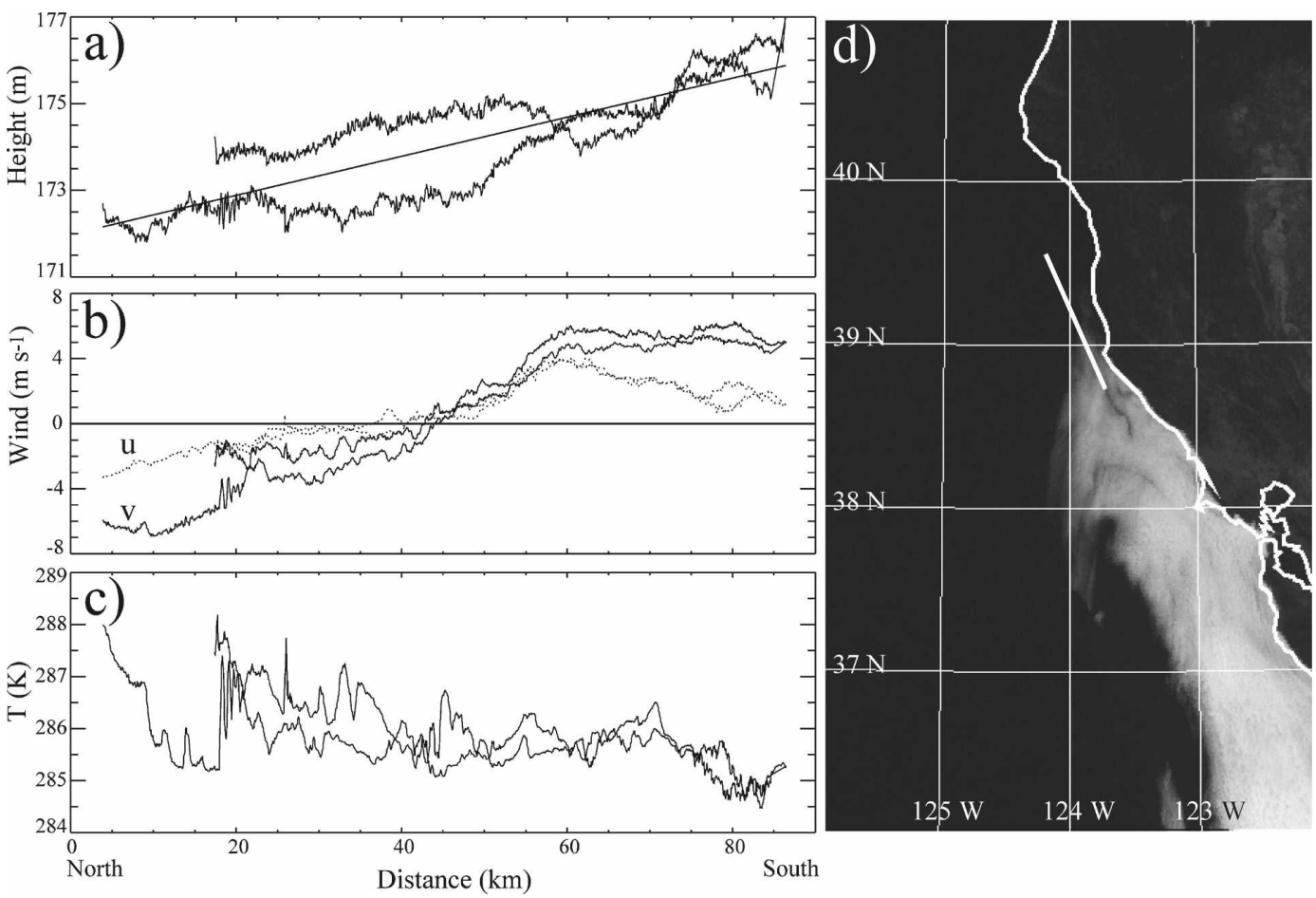

FIG. 11. The 996-hPa UWKA reciprocal legs from 1728 to 1806 UTC 23 Jun 2006 depicting (a) GPS heights of the isobaric surface and least squares linear fit (m), (b) cross-shore ( $u$, dotted line) and alongshore ( $v$, solid line) wind components $\left(\mathrm{m} \mathrm{s}^{-1}\right)$, (c) potential temperature $(\mathrm{K})$, and (d) flight track shown by white line in visible satellite imagery from 1800 UTC 23 Jun 2006.

1994 CTWR. Others have proposed that the depth of the MBL should increase owing to topographic blocking. To investigate the cross-shore changes, isobaric legs were conducted. Figure 12 illustrates the results from the flight leg from 1856 to 1914 UTC that was directed in a primarily cross-shore direction. This leg was the last maneuver of the first flight along a heading toward Santa Rosa for refueling and the track was constrained by air traffic control. The flight leg was along a line roughly perpendicular to the stratus layer but at an angle of about $40^{\circ}$ to the coastline. The flight leg starts just west of the CTWR where winds are northerly. As the UWKA passes $35 \mathrm{~km}$, the southerly wind components begin. Least squares linear fit to the isobaric height data show a downward slope to the east, but that is largely the influence of the northerly wind regime on the western end. It is surprising however that little detectable isobaric height rise is present within the CTWR layer. From $40 \mathrm{~km}$ to the eastern end of the leg, about $20 \mathrm{~km}$ from the coast, heights show a slight increase that is especially apparent near the easternmost region. Still the vertical scale shown in Fig. 12 is only 5 $\mathrm{m}$ suggesting that pressure rises of about $0.2 \mathrm{hPa}$ are possible in the cross-shore direction within the CTWR.

Wind components as measured from the UWKA during the leg show relatively uniform speeds within the CTWR of 0 to $-1 \mathrm{~m} \mathrm{~s}^{-1}$ in the cross-shore direction and about $4 \mathrm{~m} \mathrm{~s}^{-1}$ in the alongshore direction. Potential temperatures along the leg show the CTWR layer to be about $3 \mathrm{~K}$ cooler than the environment to the west, implying a density gradient along the edge of the southerly surge that is collocated with the layer of stratus.

To check on the nearly flat cross-shore PGF, additional flights were conducted in the afternoon. As an example, Fig. 13 shows the results of the cross-shore reciprocal legs conducted at $998 \mathrm{hPa}$ near the head of the CTWR just to the north of Point Arena from 2202 to 2218 UTC. For this pair of legs, the UWKA was able to cross the CTWR in direction nearly orthogonal to the local coastline and reach within $10 \mathrm{~km}$ of the coast. Isobaric heights show a complicated pattern for both legs but reveal little height increase toward the east, suggesting again that the PGF is essentially flat. Wind components in both directions are weak and southerly components are restricted to the last third of the leg where potential temperatures show a decrease of about $1 \mathrm{~K}$. This leg emphasizes that near the head of the CTWR for this case that the flows are essentially density currents moving in response to an ageostrophic acceleration. 


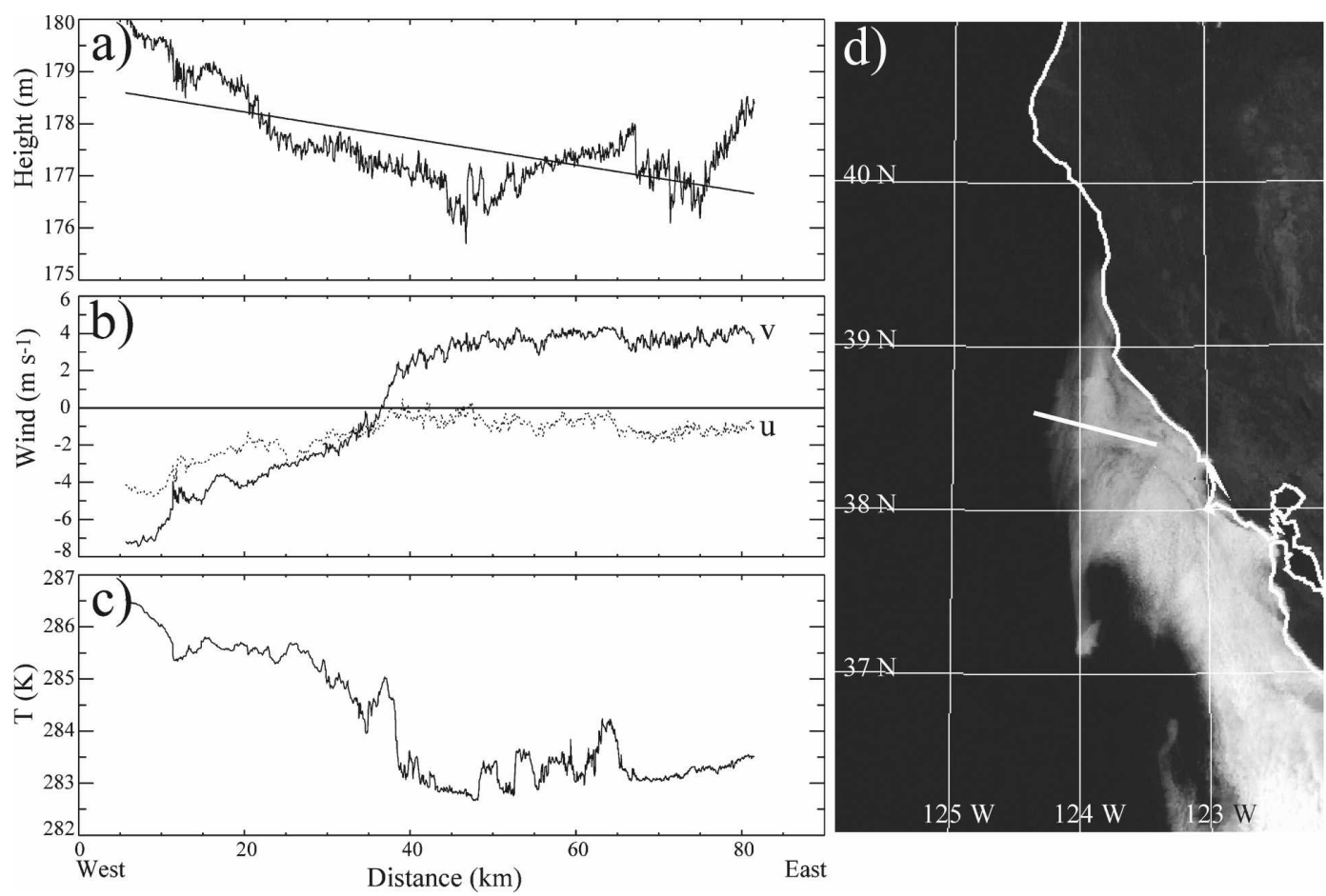

FIG. 12. As in Fig. 10, but for the 996-hPa leg from 1856 to 1914 UTC 23 Jun 2006 and visible satellite imagery from 1900 UTC 23 June.
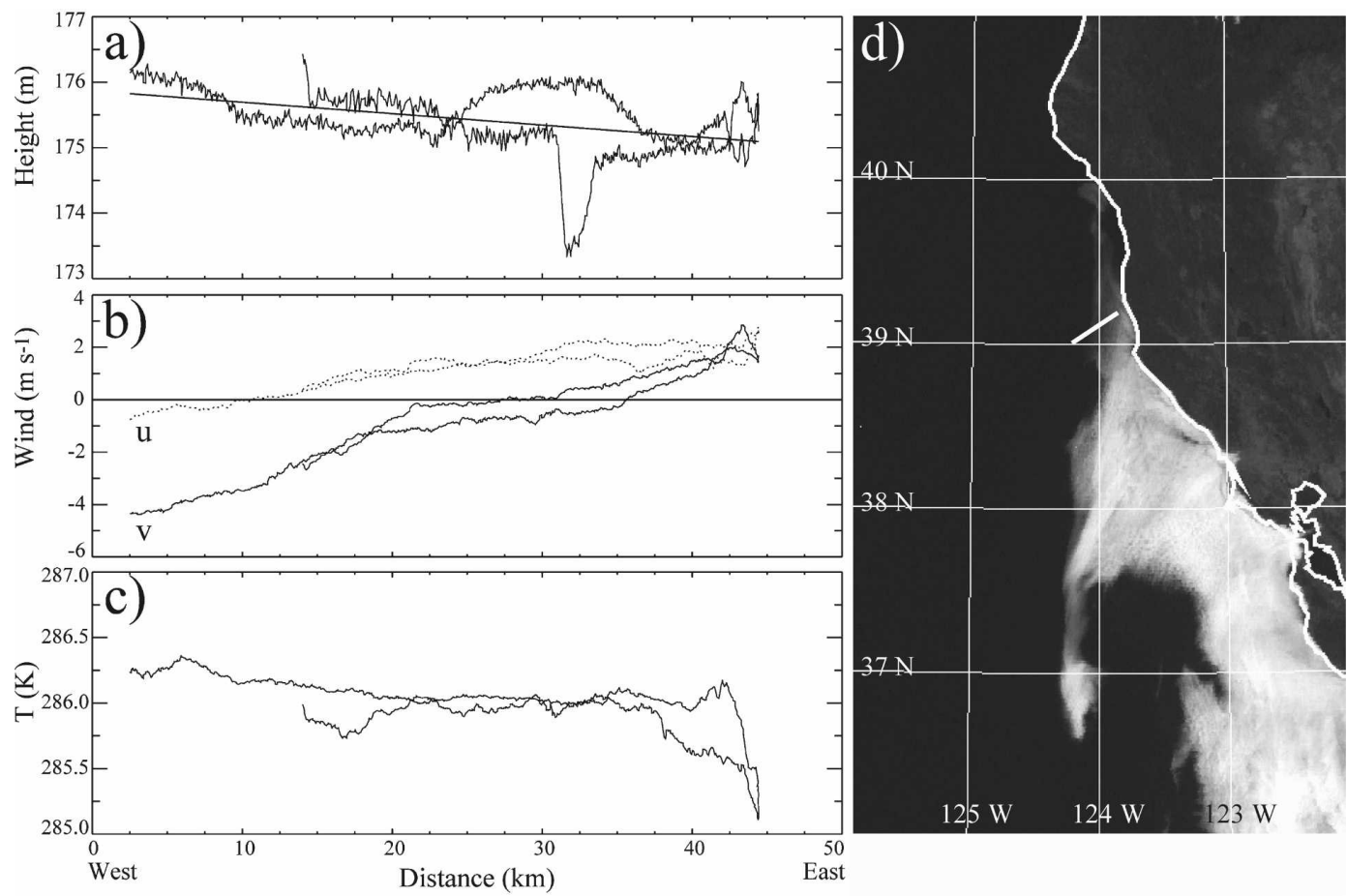

FIG. 13. As in Fig. 10, but for the 996-hPa leg from 2202 to 2218 UTC 23 Jun 2006 and visible satellite imagery from 2200 UTC 23 Jun 2006. 

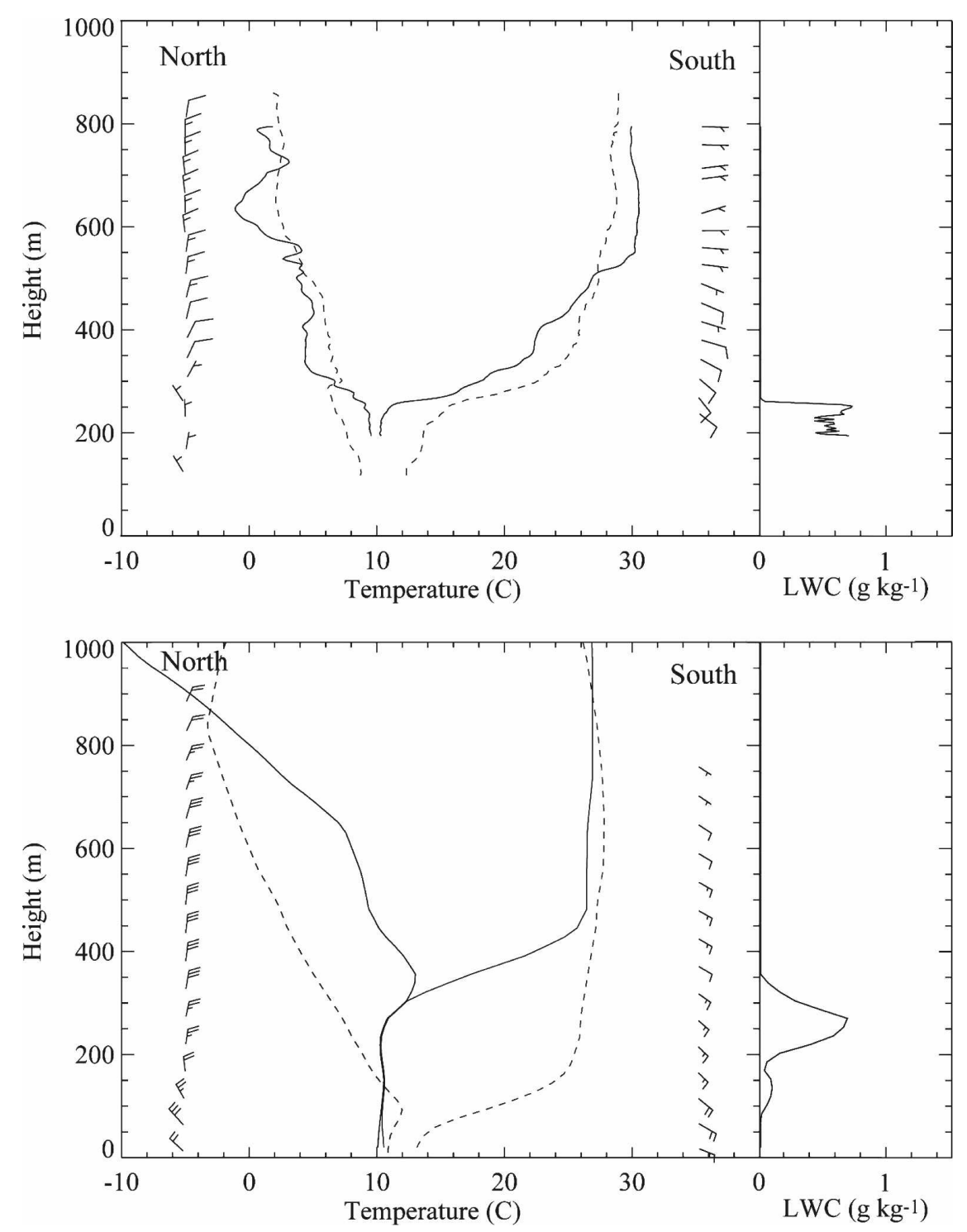

FIG. 14. Soundings of temperature and dewpoint $\left({ }^{\circ} \mathrm{C}\right)$, wind $\left(\mathrm{m} \mathrm{s}^{-1}\right)$, and $\mathrm{LWC}\left(\mathrm{g} \mathrm{kg}^{-1}\right)$ for (top) observations and (bottom) model from 23 Jun 2006. Northern soundings (dashed) taken at $1700 \mathrm{UTC}$ at $39.5^{\circ} \mathrm{N}, 124.2^{\circ} \mathrm{W}$. Southern soundings (solid) are taken at $1730 \mathrm{UTC}$ at $38.3^{\circ} \mathrm{N}$, $123.4^{\circ} \mathrm{W}$.

UWKA observations also provide an opportunity to compare with results of the WRF simulation. As an example, Fig. 14 illustrates soundings taken by the UWKA at about 1700 UTC 23 June just to the north of the CTWR and to the south of the reversal within the cloud layer and those from the WRF simulation. The general structure of the soundings in the CTWR environment is well replicated in the WRF simulation. Note that the cloud top and MBL top, LWC, wind components, and temperatures to the north of the CTWR and within the head of the reversal are well simulated.

\section{The role of clouds in the forcing of the 22-25 June 2006 CTWR event}

Clouds have often been regarded as a consequence of the CTWRs, thus not contributing substantially to the forcing. Results from the UWKA flights and WRF simulations suggest otherwise. Inspection of model results such as shown in Fig. 6 show that the isotherms are tied to the stratus layer. Strong nocturnal cooling occurs that is the result of longwave radiative flux divergence at the top of the cloud layer that marks the CTWR boundary. This suggests that the stratus tongue 
may not simply be a passive tracer of the CTWR but rather may be critical to its propagation.

Previous work on marine stratus (D. Leon 2007, personal communication) has indicated that radiative flux divergence at the top of the marine stratus layer at night is on the order of $100 \mathrm{~W} \mathrm{~m}^{-2}$, sufficient to cool a 250-m layer by more than $1^{\circ} \mathrm{C} \mathrm{h}^{-1}$. Estimates of nighttime cloud-top cooling from Oliver et al. (1978) suggest considerably larger rates are possible. Given that the CTWR layer is well mixed, cooling at the top will promote overturning of the entire layer and thereby transfer the effects of the longwave cooling throughout the entire column. This process is described in Oliver et al. (1978) who also report the diurnal cycle of the cloudtopped boundary layer height, which is highest in early morning and lowest in late afternoon. This finding is opposite of a cloud-free boundary layer with heights lowest in the morning and highest in the afternoon (Lewellen et al. 1974). A cloud-topped boundary layer is shown again in a more recent and sophisticated modeling study by Caldwell et al. (2005) who note that the cooling is fundamental to the entrainment of ambient air at the cloud top. Cloud radiative forcing can therefore serve to effectively cool and thicken the CTWR column and thereby increase the density contrast between the CTWR layer and the ambient environment, especially overnight and into the morning. The observed nighttime increases in stratus extent (e.g., Fig. 3b) and WRF-simulated status thickness (Fig. 8b) indicate the enhanced forcing after sunset. Cloud-top radiative cooling is consistent with the intensification of the CTWR movement at night. Initiation of the wind reversal tends to occur during night or morning (Bond et al. 1996), which is when the cloud forcing would be at a maximum.

Characteristics of the fog and low clouds associated with CTWRs have been rigorously examined in Thompson et al. (2005). Several important points were made including the importance of radiative cooling and surface fluxes. The idea that cold sea surface temperatures (SSTs) are responsible for fog and cloud formation was called into question. The authors argue that boundary layer depth is primarily regulated by the buoyancy generation due to surface fluxes and in-cloud processes. In their work it was noted that interaction between clouds and radiation is critical for proper MBL evolution.

Other studies have addressed the more general radiation effects. Reason et al. (2001) explored the diurnal diabatic effects of radiation using model sensitivity studies. It was found that the no-radiation simulations weakened the alongshore temperature gradient by decreasing the offshore warm air advection to the north and decreasing the cloud-top radiative cooling to the south. It was found however that the radiative cooling at cloud top was secondary to the warm air advection of the continently heated air. Mass and Steenburgh (2000) concluded that both temperature advection and downslope subsidence are important in coastal warming.

Observations and model results point to the importance of the stratus layer in the establishment and persistence of the CTWR density contrast for the 22-25 June 2006 case. To illustrate the impact of the stratus layer on the CTWR, WRF soundings from nighttime hours 0700 (solid) and 0900 (dashed) UTC 23 June 2006 are compared (Fig. 15). While these are at a fixed point and not in a Lagrangian frame of reference, which would be a $30-\mathrm{km}$ difference given the propagation speed of $4.25 \mathrm{~m} \mathrm{~s}^{-1}$, they should still be representative. During the 2-h period, the boundary layer deepens 50 $\mathrm{m}$ and cools by $1^{\circ}-2^{\circ} \mathrm{C}$ while the total LWC increases, indicating that the cloud thickness is increasing. Beneath the strong inversion the WRF temperature profile parallels the dry adiabatic lapse rate. Radiative cooling at the cloud top would thus create negatively buoyant parcels and a subsequent mixing, leading to a deeper and continued well-mixed (dry adiabatic) MBL over time. The sounding also suggests some warming and drying above $500 \mathrm{~m}$ that is likely associated with the large-scale subsidence occurring (not shown). While the boundary layer deepens and cools due to the cloud radiative forcing, subsidence prevails above the boundary layer. By contrast, Fig. 16 reveals the vertical profile to the north in the cloud-free region at the same two times. Here, the MBL becomes shallower over this 2-h period and slightly warms above $100 \mathrm{~m}$.

Cloud-top cooling associated with the CTWR stratus also plays a role in modulation of the nighttime surface pressure field. Observations reveal that the stratus thickness and extent are enhanced and the CTWR accelerates northward during the night. This can be explained by Fig. 17, which compares the cooling at the 996-hPa level from 0200 UTC (1900 local time) 23 June to 1400 UTC (0100 local time) 23 June 2006 with the attendant changes in the surface pressure field (same period shown in Figs. 6a,c). If the diabatic cooling associated with clouds is significant, the changes in the surface pressures must reflect such effects. Isallobars in Fig. 17 follow trends in the 996-hPa temperatures during the initial nighttime cooling with the largest pressure changes associated with the greatest cooling near the head of the CTWR. This indicates that the horizontal pressures must increase as a result of the diabatic cooling within the CTWR and that the horizontal pressure gradient force becomes enhanced at night. Note that at the head of the CTWR the isallobars are packed 


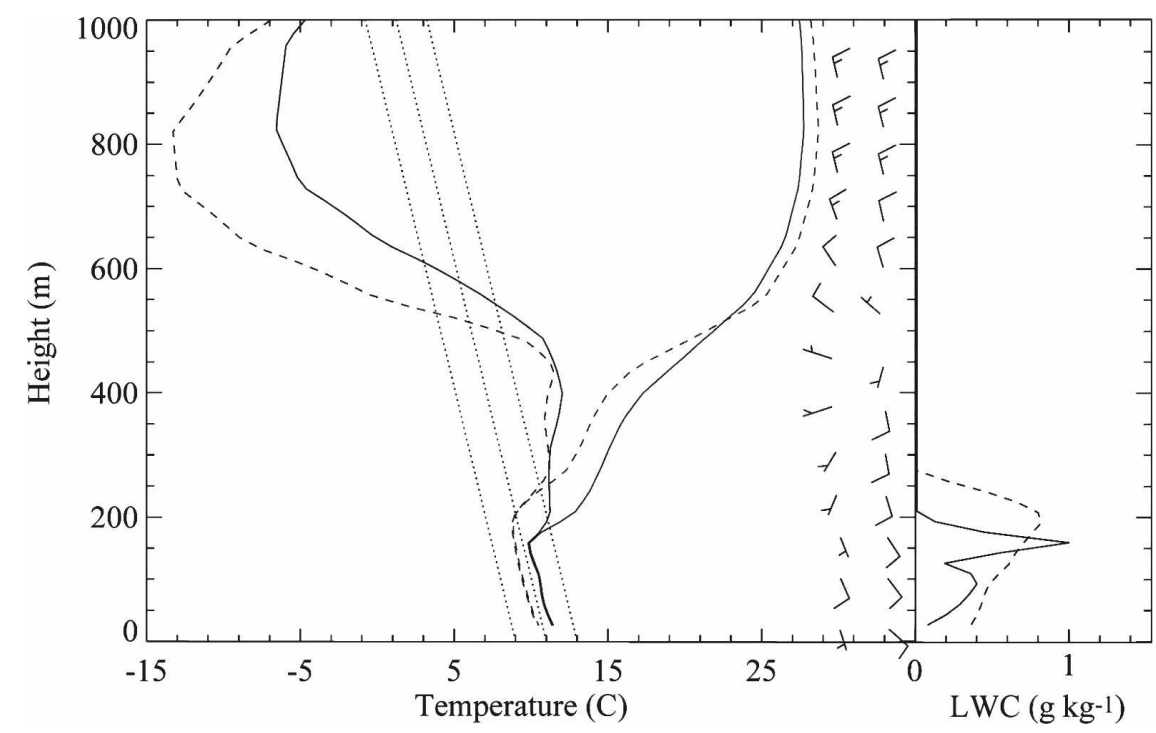

FIG. 15. Model soundings at $36^{\circ} \mathrm{N}, 122^{\circ} \mathrm{W}$ depicting temperature and dewpoint $\left({ }^{\circ} \mathrm{C}\right)$ at 0700 UTC 23 Jun (solid line) and 0900 UTC 23 Jun 2006 (dashed line). Dry adiabatic lines (dotted) are included. Wind barbs for the two times are shown in meters per second with the earlier time on the left. LWC $\left(\mathrm{g} \mathrm{kg}^{-1}\right)$ is plotted on the right.

tightly together, implying a strong ageostrophic response as a result of the modulation in the horizontal pressure field. It is not surprising that a northward surge occurs in response to such cooling. It is apparent that changes in the horizontal pressure field accompanying the CTWR evolution are strongly tied to the cooling of the CTWR layer and that clouds are a critical component of the propagation mechanism.

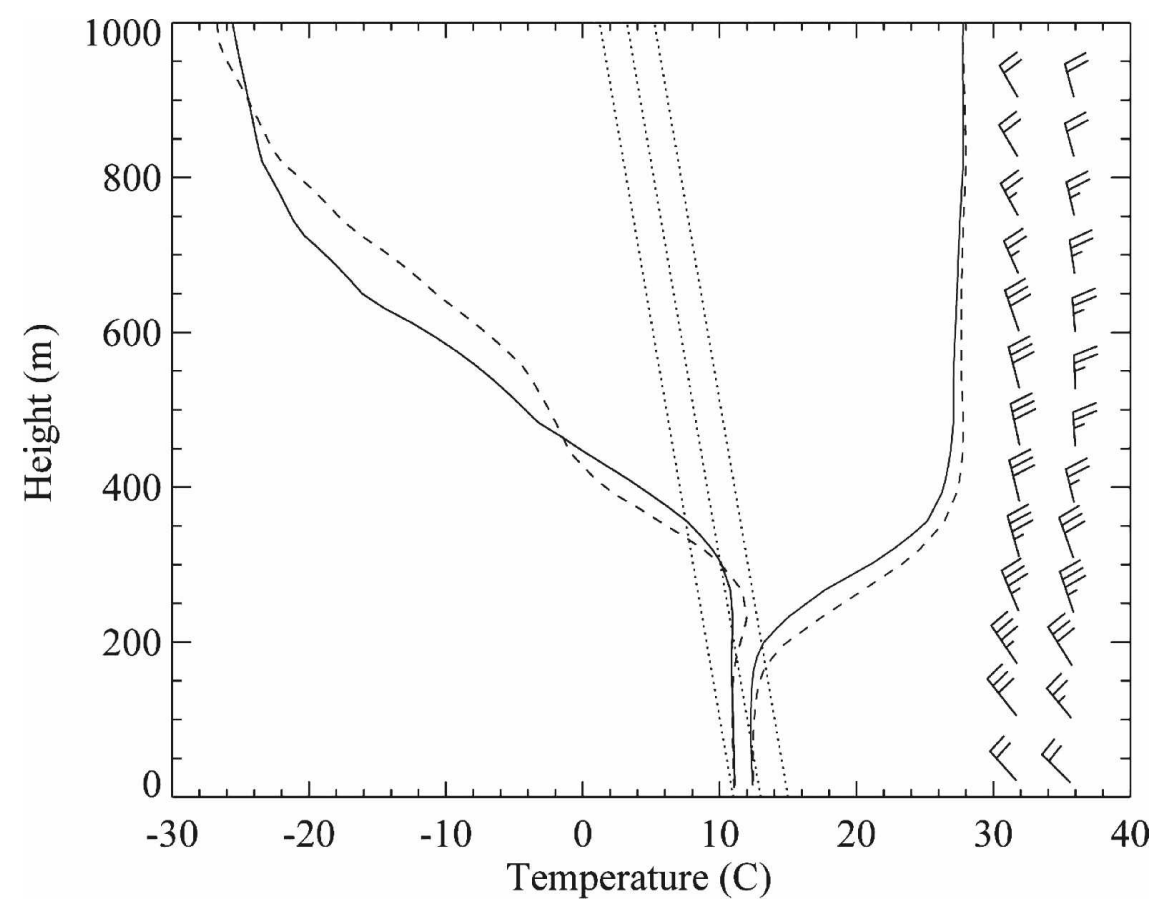

FIG. 16. Model soundings at $38^{\circ} \mathrm{N}, 124^{\circ} \mathrm{W}$ depicting temperature and dewpoint at $0700 \mathrm{UTC}$ 23 Jun (solid line) and 0900 UTC 23 Jun 2006 (dashed line). Dry adiabatic lines (dotted) are included. Wind barbs for the two times are shown in meters per second with the earlier time on the left. 


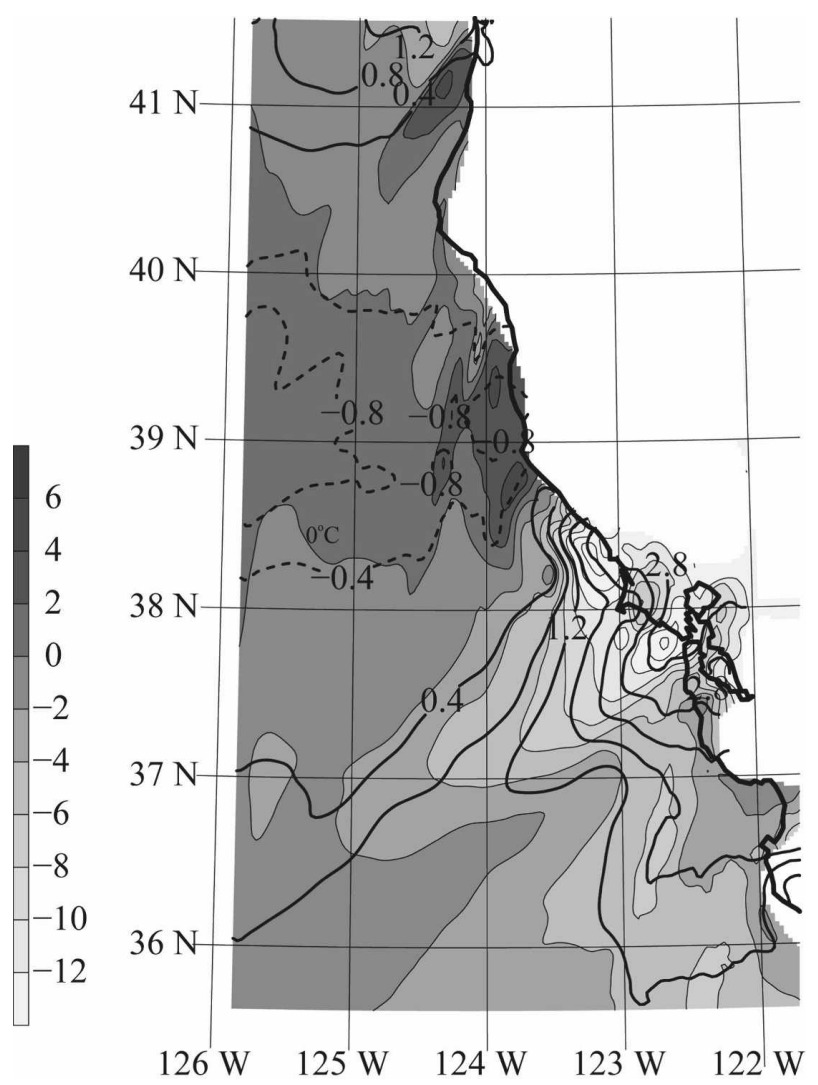

FIG. 17. WRF simulations of $996-\mathrm{hPa}$ temperature change (shaded, thin solid lines; K) and changes in the surface pressure field (thick solid lines; hPa) from 0200 UTC (1900 local time) to 1400 UTC (0100 local time) 23 Jun 2006.

It is important to note that the cooling and mixing of the MBL by the radiative cooling at cloud top and concurrent lowering of the MBL in the cloud-free regions to the north increases the temperature gradient and MBL depth gradient. This implies that the density gradient between the cloudy CTWR layer and the adjacent cloud-free environment to the north will become sharper. It is the combination of subsidence that is the result of synoptic forcing and cloud-top radiative cooling within the CTWR layer that is responsible for increasing the density contrast at the CTWR edge. Valuable buoy observations aid the analysis and are presented here as observations that span the $24 \mathrm{~h}$ preceding and the $48 \mathrm{~h}$ following the wind reversal (Fig. 18). Figure 18a illustrates the alongshore wind and reveals a rapid transition from northerly to southerly wind after the reversal. The two critical observations taken at the buoys are the air and water temperature taken at a height of $4 \mathrm{~m}$ and a depth of $0.6 \mathrm{~m}$. Prior to the reversal, the average air temperature is between $0.5^{\circ}-1^{\circ} \mathrm{C}$ warmer than the water. A rapid drop in air temperature by about $1{ }^{\circ} \mathrm{C}$ occurs after the wind rever-
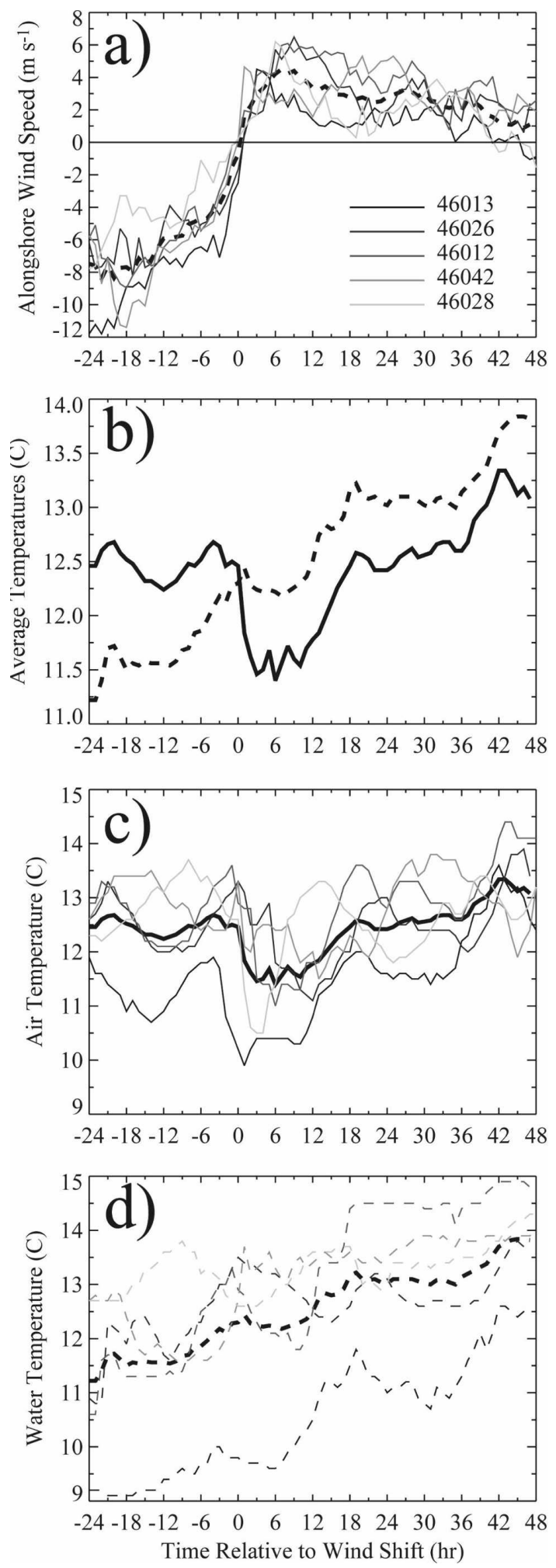

FIG. 18. Buoy observations relative to the time of wind reversal. Observations consist of the (a) alongshore $\left(330^{\circ}\right)$ wind component $\left(\mathrm{m} \mathrm{s}^{-1}\right),(\mathrm{b})$ average air and sea temperature $\left({ }^{\circ} \mathrm{C}\right),(\mathrm{c})$ air temperature $\left({ }^{\circ} \mathrm{C}\right)$, and $(\mathrm{d})$ water temperature $\left({ }^{\circ} \mathrm{C}\right)$. Individual observations are indicated by thin lines and are shaded to correspond to a buoy as shown in (a). Averages are indicated by thick lines. 
sal, demonstrating the temperature change associated with the CTWR. Another key feature is the fairly consistent warming of the ocean from $11.5^{\circ} \mathrm{C}$ seen a day prior to the reversal to $13.5^{\circ} \mathrm{C}$ two days after the reversal. This is possibly explained by the diminishing Ekman pumping from the northerly wind stress that has decreased steadily beginning $24 \mathrm{~h}$ prior to the actual reversal. The initial temperature difference is the air being half of a degree warmer than the ocean. After the wind reversal, the water becomes warmer than the air by $0.5^{\circ}-1.0^{\circ} \mathrm{C}$. This supports the assertion by Thompson et al. (2005) that cold SSTs are not responsible for the initial fog and cloud formation, since SSTs are warmer than the air. In addition, it supports the idea that the cooling is primarily due to cloud-top radiation and not from losing energy to the ocean since SSTs are warmer than the air temperature. The fact that the ocean is warmer than the air may also help keep the MBL well mixed.

\section{Summary and conclusions}

Numerical simulations and aircraft observations of the 22-25 June 2006 CTWR have provided a detailed look into the structure and forcing responsible for the propagation of this wind reversal. As noted by numerous authors, the role of the synoptic environment in preconditioning the coastal environment is critical. Synoptic forcing is responsible for initiation of strong offshore flow that alters the ambient pressure field in the coastal environment such that a PGF that is near zero or even directed to the north becomes established. Results of the WRF simulation suggests that clouds, through longwave cooling at the top of the stratus layer, play an active role in enhancing the density contrast between the cloudy CTWR layer and the ambient environment. Cooling at the top of a layer with a dry adiabatic temperature profile prompts mixing throughout the entire column and thereby acts to deepen the boundary layer. Such a cooling enhances the density contrast during the nighttime hours and is one reason for a diurnal differential propagation speed of the CTWR. The juxtaposition of subsidence warming ahead of the CTWR and nighttime radiative cooling within the cloudy air helps establish a sharp density contrast along the northern edge of the reversal. The northward progression of the CTWR on 23 June 2006 can be understood as a density current moving in response to the existing density gradient.

Both WRF simulations and UWKA observations show that the flow is highly ageostrophic near the head of the CTWR. The PGF near the head of the CTWR is directed northward, showing that the winds are di- rected downgradient. Within the CTWR the force balance is primarily antitriptic. Little cross-shore variation in MBL height or pressure is simulated and UWKA measurements support the simulations. This suggests that the blocking effects by the coastal terrain do not require a large horizontal pressure signal in a direction normal to the terrain to effectively direct the flows northward. Little evidence of the CTWR being rotationally trapped by Coriolis effects was seen. This is not to say that the force balance several hundred kilometers to the south of the CTWR head does not show evidence of Coriolis influences, but rather that such trapping does not appear to be the primary cause for the northward propagation for the 22-25 June 2006 event. Cyclonic circulation develops on 23 June although it is likely a response to the localized area of warm temperatures behind Point Arena and not the reason for the CTWR propagation, but rather a consequence of it.

Acknowledgments. This research was supported in part by the Office of Naval Research through Grant N000140510720 and the National Science Foundation through Grant ATM-0332202. The authors acknowledge Zhien Wang for the additional computer resources to run WRF, pilots Don Cooksey and Kevin Fagerstrom, and scientists Jeff French and Jeff Snider for help with the field measurements.

\section{REFERENCES}

Bane, J. M., 1997: Airflow and stratification in propagating southerly surges within the summertime marine layer off California and Oregon. Preprints, 12th Symp. on Boundary Layers and Turbulence, Vancouver, BC, Canada, Amer. Meteor. Soc., 346-347.

Beardsley, R. C., C. E. Dorman, C. A. Friehe, L. K. Rosenfield, and C. D. Wyant, 1987: Local atmospheric forcing during the Coastal Ocean Dynamics Experiment 1: A description of the marine boundary layer and atmospheric conditions over northern California upwelling region. J. Geophys. Res., 92, $1467-1488$.

Bond, N. A., C. A. Mass, and J. E. Overland, 1996: Coastally trapped wind reversals along the U.S. West Coast during the warm season. Part I: Climatology and temporal evolution. Mon. Wea. Rev., 124, 430-445.

Burk, S. D., and W. T. Thompson, 1996: The summertime lowlevel jet and marine boundary layer structure along the California coast. Mon. Wea. Rev., 124, 668-686.

$\longrightarrow$, and —, 2004: Mesoscale eddy formation and shock features associated with a coastally trapped disturbance. Mon. Wea. Rev., 132, 2204-2223.

Caldwell, P., C. S. Bretherton, and R. Wood, 2005: Mixed-layer budget analysis of the diurnal cycle of entrainment in southeast Pacific stratocumulus. J. Atmos. Sci., 62, 3775-3791.

Dorman, C. E., 1985: Evidence of Kelvin waves in California's marine layer and related energy generation. Mon. Wea. Rev., 113, 827-839. 
— 1987: Possible role of gravity currents in northern California's coastal summer wind reversals. J. Geophys. Res., 92, 1497-1506.

Guan, S., P. L. Jackson, and C. J. C. Reason, 1998: Numerical modeling of a coastal trapped disturbance. Part I: Comparison with observations. Mon. Wea. Rev., 126, 972-990.

Jackson, P. L., C. J. C. Reason, and S. Guan, 1999: Numerical modeling of a coastal trapped disturbance. Part II: Structure and dynamics. Mon. Wea. Rev., 127, 535-550.

Lewellen, W. S., M. E. Teske, and C. duP. Donaldson, 1974: Turbulence model of diurnal variations in the planetary boundary layer. Proc. 1974 Heat Transfer and Fluid Mechanics, Palo Alto, CA, Stanford University, 301-319.

Mass, C. F., and M. D. Albright, 1987: Coastal southerlies and alongshore surges of the west coast of North America: Evidence of mesoscale topographically trapped response to synoptic forcing. Mon. Wea. Rev., 115, 1707-1738.

— the West Coast during the warm season. Part II: Synoptic evolution. Mon. Wea. Rev., 124, 446-461.

— cal study of an orographically trapped wind reversal along the West Coast of the United States. Mon. Wea. Rev., 128, 2363 2397.

Nuss, W. A., 2007: Synoptic-scale structure and character of coastally trapped wind reversals. Mon. Wea. Rev., 135, 60-81.

— , and Coauthors, 2000: Coastally trapped wind reversals: Progress toward understanding. Bull. Amer. Meteor. Soc., 81, 719-743.

Oliver, D. A., W. S. Lewellen, and G. G. Williamson, 1978: The interaction between turbulent and radiative transport in the development of fog and low-level stratus. J. Atmos. Sci., 35, 301-316.

Parish, T. R., 2000: Forcing of the summertime low-level jet along the California coast. J. Appl. Meteor., 39, 2421-2433.

—, M. D. Burkhart, and A. R. Rodi, 2007: Determination of the horizontal pressure gradient force using global positioning system onboard an instrumented aircraft. J. Atmos. Oceanic Technol., 24, 521-528.

— D. A. Rahn, and D. Leon, 2008: Aircraft observations of a coastally trapped wind reversal off the California coast. Mon. Wea. Rev., 136, 644-662.

Pomeroy, K. R., and T. R. Parish, 2001: A case study of the interaction of the summertime coastal jet with the California topography. Mon. Wea. Rev., 129, 530-539.
Rahn, D. A., and T. R. Parish, 2007: Diagnosis of the forcing and structure of the coastal jet near Cape Mendocino using in situ observations and numerical simulations. J. Appl. Meteor. Climatol., 46, 1455-1468.

Ralph, F. M., L. Armi, J. M. Bane, C. E. Dorman, W. D. Neff, P. J. Neiman, W. A. Nuss, and P. O. G. Persson, 1998: Observations and analysis of the 10-11 June 1994 coastally trapped disturbance. Mon. Wea. Rev., 126, 2435-2465.

- , and Coauthors, 2000: Kelvin waves and internal bores in the marine boundary layer inversion and their relationship to coastally trapped wind reversals. Mon. Wea. Rev., 128, 283 300.

Reason, C. J. C., and D. Steyn, 1992: The dynamics of coastally trapped mesoscale ridges in the lower atmosphere. J. Atmos. Sci., 49, 1677-1692.

_ P. L. Jackson, and H. Fu, 2000: Dynamical influence of large valleys on the propagation of coastally trapped disturbances. Meteor. Appl., 7, 247-259.

- K. K. Tory, and P. L. Jackson, 2001: A model investigation of the dynamics of a coastally trapped disturbance. J. Atmos. Sci., 58, 1892-1906.

Rodgers, D. P., and Coauthors, 1998: Highlights of Coastal Waves 1996. Bull. Amer. Meteor. Soc., 79, 1307-1326.

Samelson, R. M., and A. M. Rodgerson, 1996: Life cycle of a linear coastal-trapped disturbance. Mon. Wea. Rev., 124, 1853 1863.

Schwerdtfeger, W., 1975: The effect of the Antarctic Peninsula on the temperature regime of the Weddell Sea. Mon. Wea. Rev., 103, 41-51.

Skamarock, W. C., R. Rotunno, and J. B. Klemp, 1999: Models of coastally trapped disturbances. J. Atmos. Sci., 56, 3349-3365.

— J. B. Klemp, J. Dudhia, D. O. Gill, D. M. Barker, W. Wang, and J. G. Powers, 2005: A description of the advanced research WRF version 2. NCAR Tech. Note NCAR/TN468+STR, 88 pp.

Thompson, W. T., T. Haack, J. D. Doyle, and S. D. Burk, 1997: A nonhydrostatic mesoscale simulation of the 10-11 June 1994 coastally trapped wind reversal. Mon. Wea. Rev., 125, 32113230.

- S. D. Burke, and J. Lewis, 2005: Fog and low clouds in a coastally trapped disturbance. J. Geophys. Res., 110, D18213, doi:10.1029/2004JD005522.

Zemba, J., and C. A. Friehe, 1987: The marine boundary layer jet in the coastal ocean dynamics experiment. J. Geophys. Res., 92, 1489-1496. 